\title{
تقدير درجة التوجيه المهني لطابة الصف العاشر في مديريات تربية عمان هن وجهة نظر الطلبة أنفسهم
}

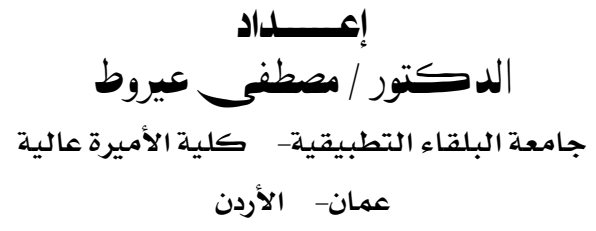

مجلة بحوث التربية النوعية - جامعة المنصورة

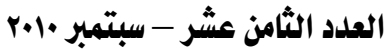




\section{تقدير درجة التوجيه المهني لطلبة الصف العاشر في هديريات تربية عمان هن وجهة نظر الطلبة أنفسهم

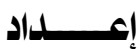 \\ * الد كُر / مصطغ عبروط}

:صغال|

هدف هذا البحث إلى تقدير درجهة التوجيه المهني لطلبة الصف العاشر يْ مديريات تربية

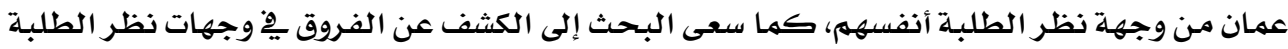

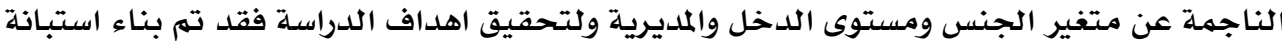

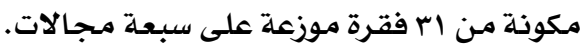

وقد تم التحقق من الصدق بعرضها على محكمهين مختصدين، وقيس الثبات باستخدام

معامل الاتساق الداخلي (كرونباخ الفا ) وكان مقدراه (سو، • ).

تكونت عينة الدراسـة من ( . .ع) طالباً وطالبة ووزعت أداة الدراسة بطريقة طبقية عشوائية

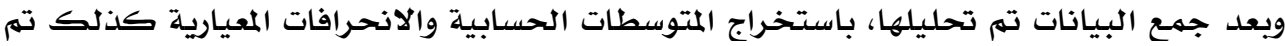

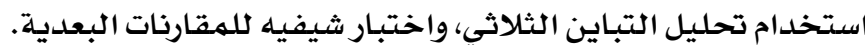

وقد بينت نتائج البحث ان درجة التوجيه والإرثاد المهنى التى يتلقاها الطلبة من المرثد

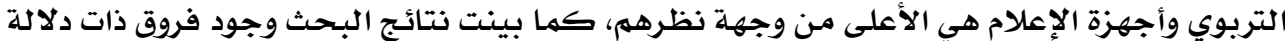

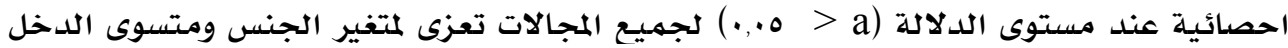
والمديريـة، وكانت تلك الفروق لصالح ذوي الدخل ( الأقل من .0م) ولمديرية تربية عمان الأولى. 


\section{ASSESSMENT OF CAREER GUIDANCE DEGREE FOR TENTH GRADE STUDENTS AMONG}

\section{AMMAN EDUCATIONAL DEPARTMENT FROM THEIR VIEW POINTS \\ Dr-Mostafa Eirout"}

\section{Abstract}

This Study aimed to assessment the career guidance degree from tenth grade students among Amman Educational Department from their view point, this study sough to examine the differences of students view point according to the following variables: gender, parent income-level, and educational department.

In order to achieve the study objective, questionnaire was designed, it consisted of (31) teams distributed over seven domains.

The questionnaire was validated by specialists, and internal consistency (Cronpach Alpha) was used to calculate reliability coefficient, it was (0.93) The study samples consisted of (400) students and a layer randomly sample was chosen. The means and slandered deviations of the responses of subjects were calculated, and three ways Anova and Scheffe multiple comparison were tests.

The findings were as follows:

- The educational counselor and advertisements instruments were the most effective domain.

- Astatically significance at $(a<0.05)$ attributed to gender, parent income- level and educational departments in all domains.

- The variance source attributed to lower income level and To Amman first educational department.

*Alia Price University-College - Al-Balqa Applied University 


\section{تقدير درجة التوجيه المهني لطلبة الصف العاشر في هديريات تربية عمان هن وجهة نظر الطلبة أنفسهم \\ إعـــــلـاد \\ الدكور / مصطفح عبروط}

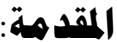

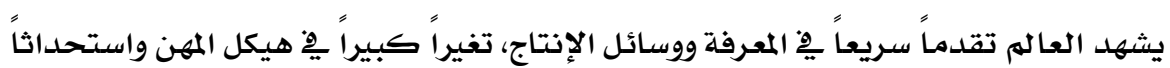

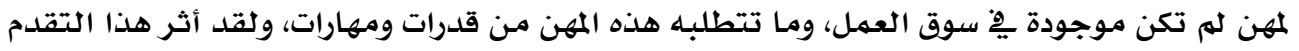

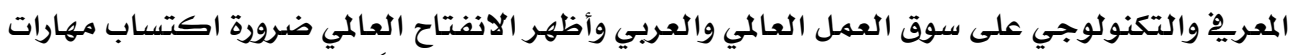

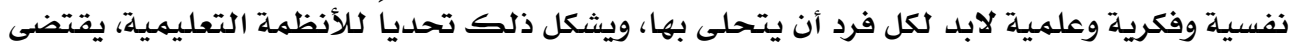

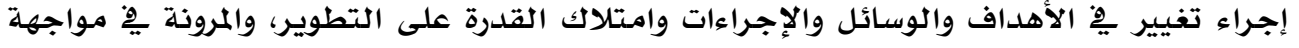

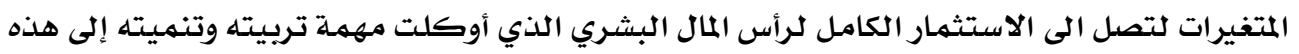
المؤسسة التي ترفد مخرجاتها كافة القطاعات الإنتاجية (Niklanovic, 2008). ويعد التكامل بين القطاعات الإنتاجية والمؤسسة التعليمية ضرورة للحد من البطاتئل البالة، وا لهدر

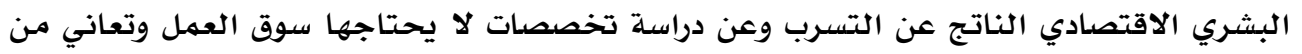

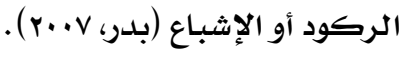

ولقد تنبه التربويون والمتخصصون الاجتماعيون إلى الاختلالات الموجودة يِّ سوق العمل

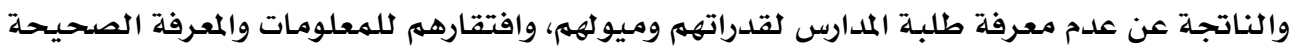

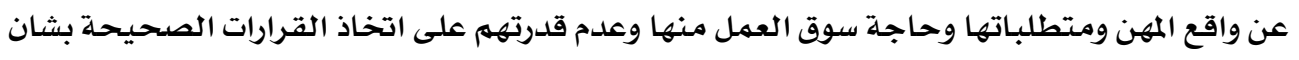
اختيار مهنة المستقبل (Guidance \& School Conuesling,2008).

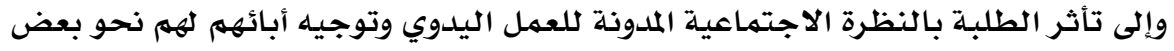

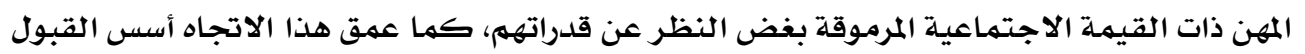

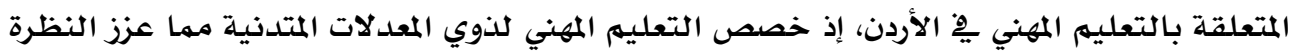

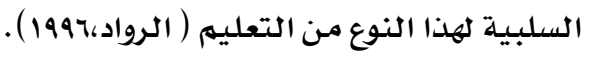

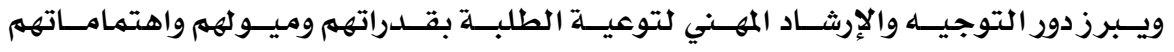
واكتسابهم القدرة على حل المثكلات واتخاذ القرار المهني المناسب لقدراتهم وميولهيهم وتكوين اتجاهـات

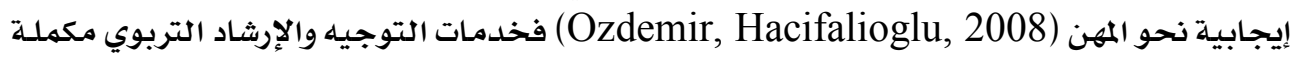

جامعة البلقاء التطبيقية- كلية الأميرة عالية - عمان- الأردن 


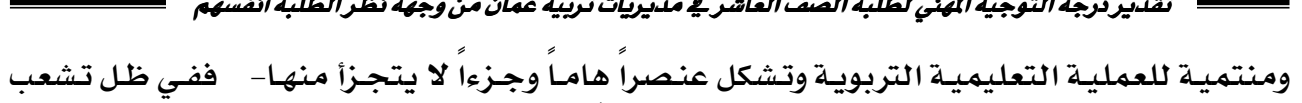

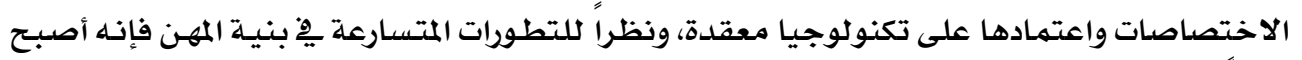

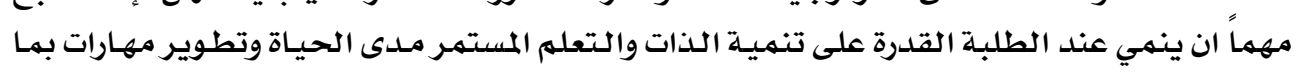

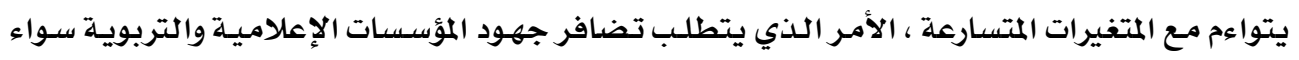

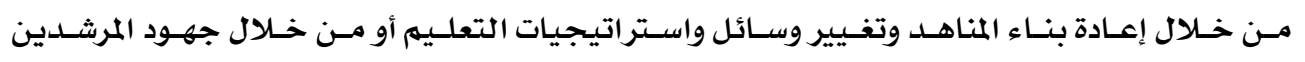

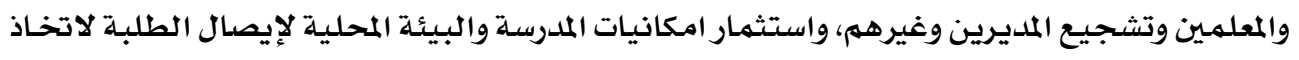

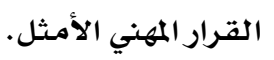
مشاكلة البحث:

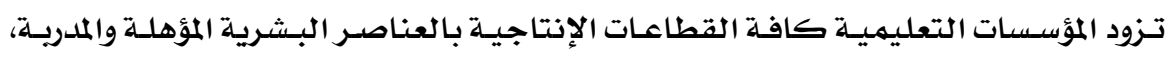

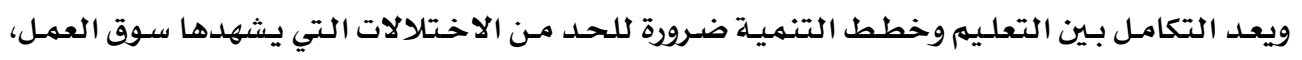

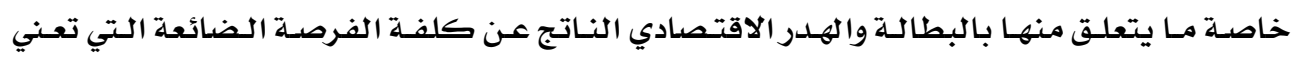

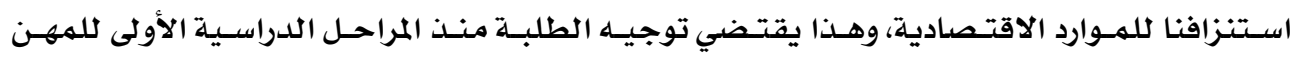

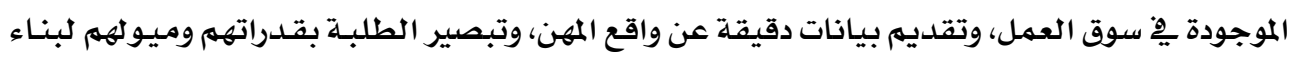
قرارات مهنية صدحيحة

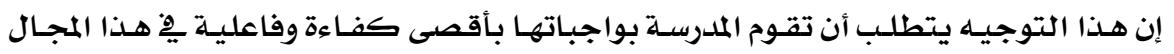

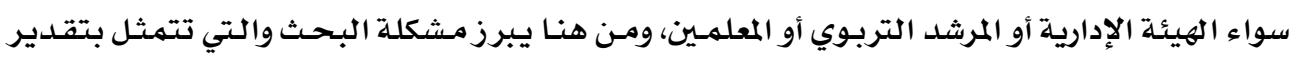

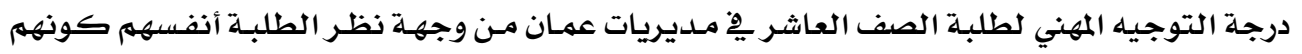

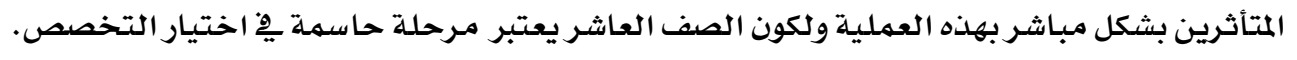

\section{أهدافـ البحث:}

هدف هذا البحثث إلى قياس درجـة التوجيه المهني لطلبة الصف العاشر الأسـاسي ِِّ مـديريات

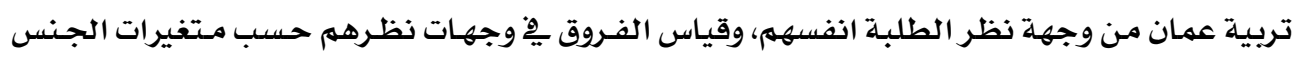
والمديرية والدخل.

أسئلة البحث:

السؤال الرئيس: ما درجة التوجيه المهني لطلبـة الصف العاشر يِّ مديريات تربية عمان من وجهـة نظر

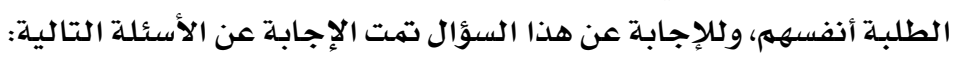

سا : مـا درجـة التوجيـه المهني لطلبـة الصف العاشـر فِ مديريات تربيـة عمان مـن وجهـة نظرالطلبـة أنفسهم؟ مأدج

سب : هل تختلف وجهات نظر طلبـة الصف العاشر يِّ مديريات تربية عمان لدرجـة التوجيـه المهني بإختلاف الجنس والدخل والمديريـة فئي 
تتبـع أهمية البحثث من كونه يهكن ان يفيد الجهات التالية:

ا- صانعي القرار مِّ وزارة التربية والتعليه: فنتائج البحث تلقي الضوء على درجة تأثير

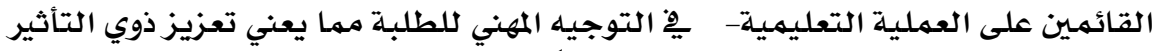

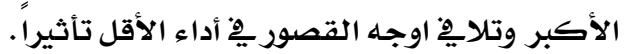

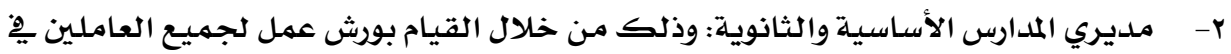
المدرسـة لمضاعفة جهودهم وتغيير أساليبهم ليكونوا أكثر أكثر فاعلية والمية وتأثيرا. ب- - المعلمـين: هذا البحث يقدم تغذية راجعة لأداء المعلمـين مهما يعني مـراجعة الذات لتطوير أساليبهم ووسـائلهم ليتواءموا مـع المستتجدات. ع- القائمـين على وسـائل الإعلام: لتكثيف جهودهم وتقديم برامج ترعوية حول مستقبل المهن وحاجات سوق العمل، وإظهار ارياب المهن والعاملين فيها بصورة محببيلة للطلبـة.

اقتصر هذا البـحث على طلبـة الصف العاشـر يِّ المدارس الحكوميـة ِِّ مـديريات تربيـة عمـان

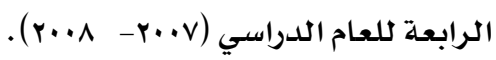

\section{التعريفات الإجرائية:}

التوجيه المهني: يقصد بالتوجيه مجموع الخدمات التربوية النفسية والاجتماعية والمهنية

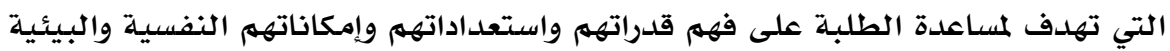

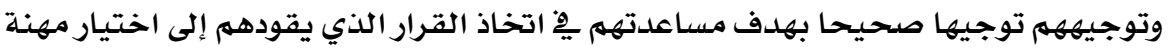

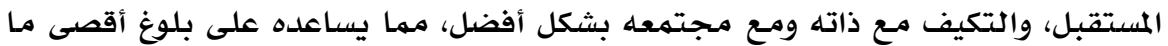

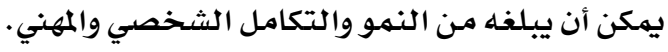
مديريات تربية عمان: وحدة إدارية ضمن الهيكل الإداري لوزارة التربية والتعليهم ويهدف إلى

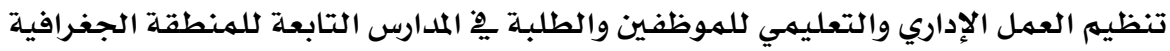
التي تشرف عليها المديرية، وتتكون من عدة أقسام فرعية كشؤون الموظفين والطلبة والامتحانات والشؤون المالية والإدارية... الخئ.

الإطار النظطري:

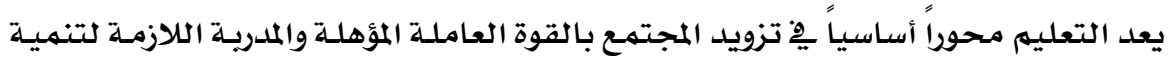

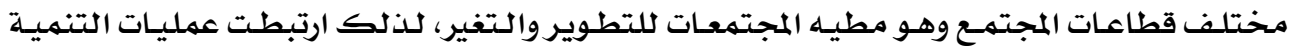




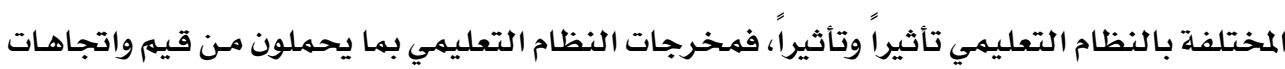

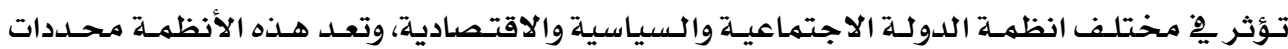

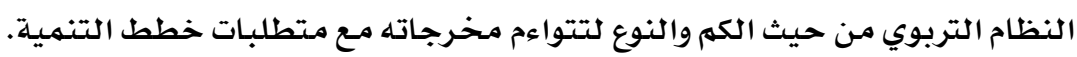

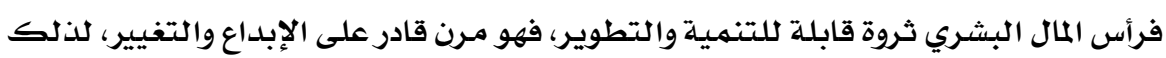

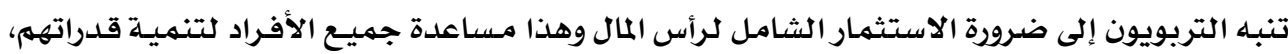

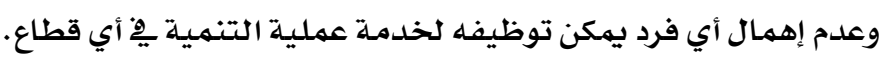

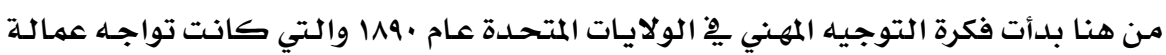

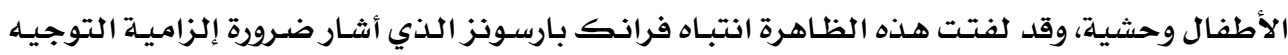

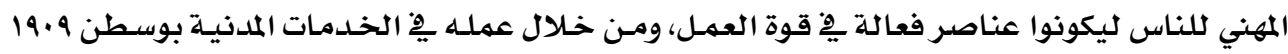

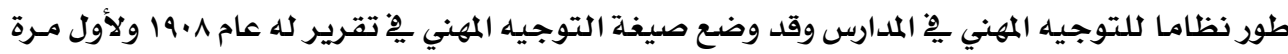

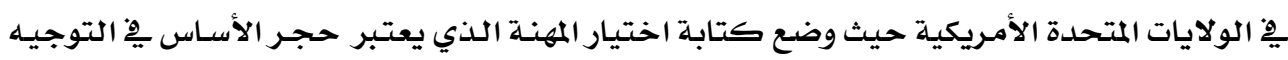

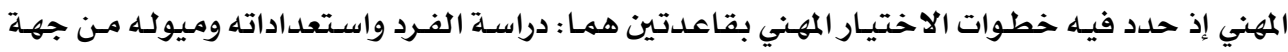

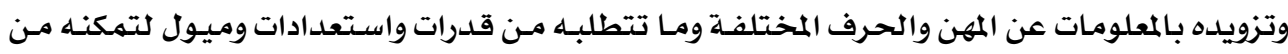
اختيار المهنة الملائمة او أية حرفة المن والهن الحرف الحرف.

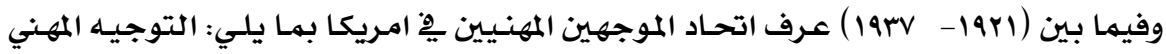

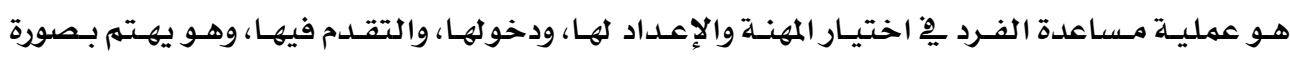

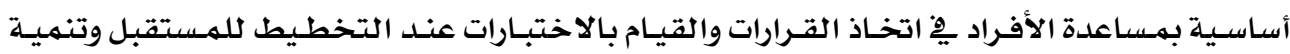

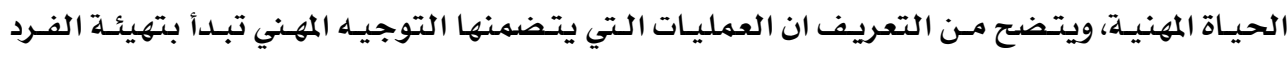

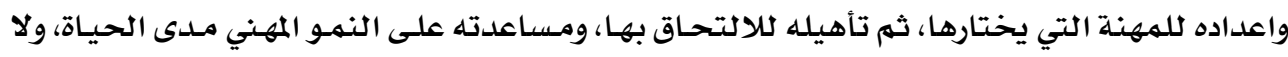

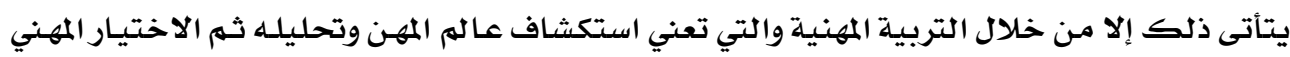
.(Smith,2008)

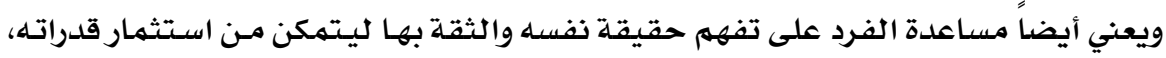

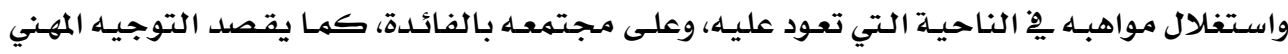

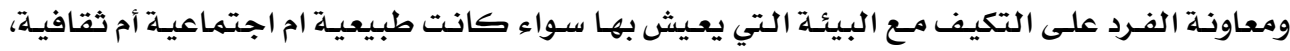

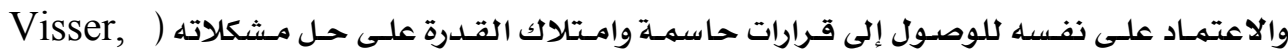

.(Dierolf,2004

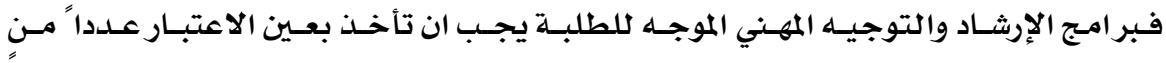

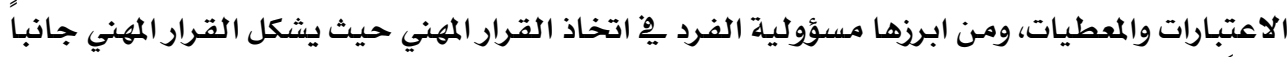

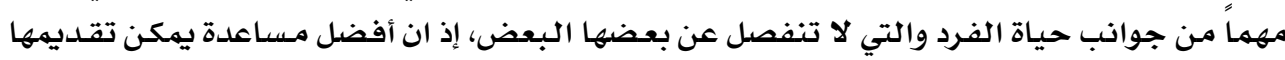

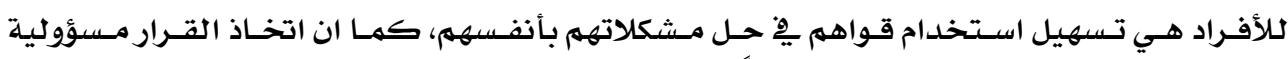

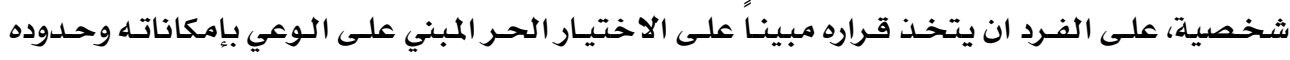




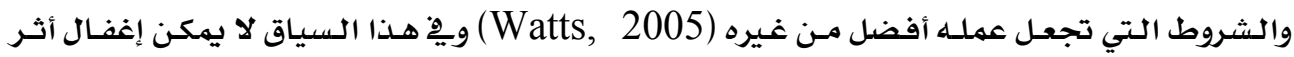

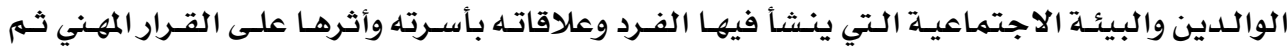

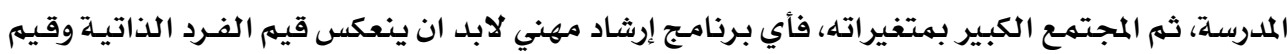

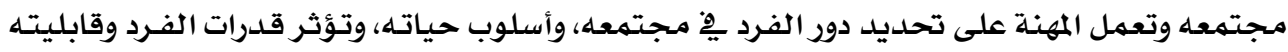

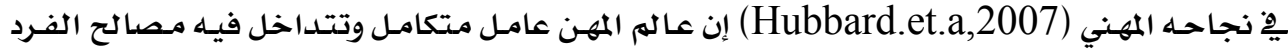

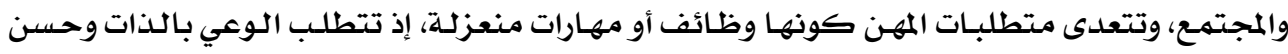

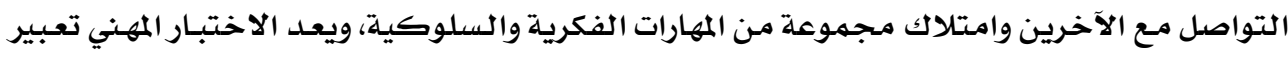

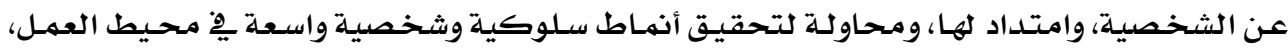

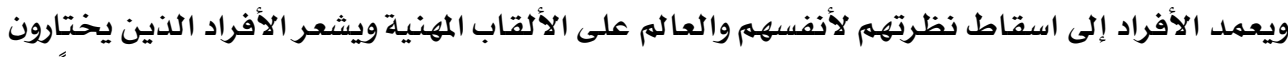

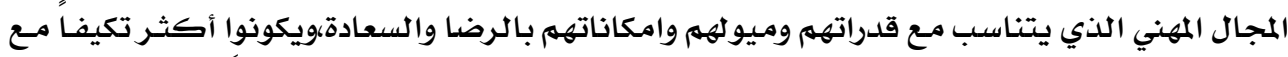

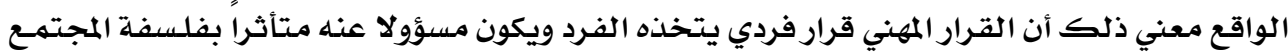

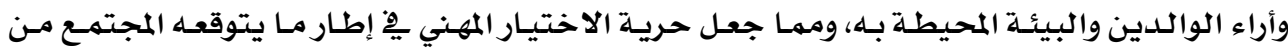
الفرد وما يتوقعه الفرد من المهنة.

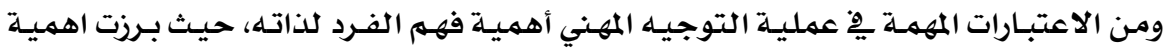

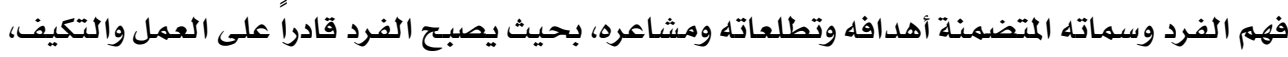

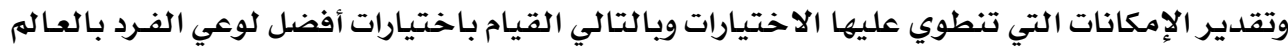

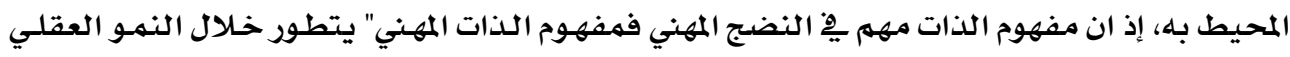

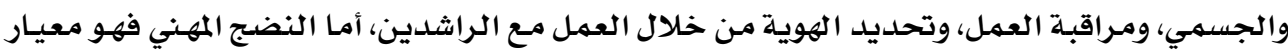

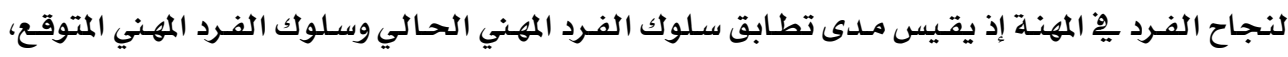

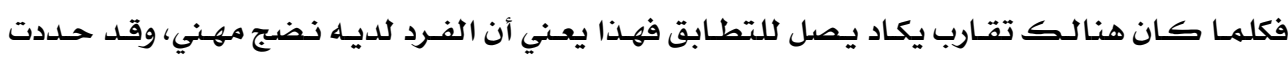

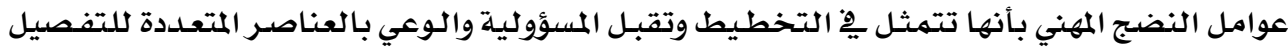

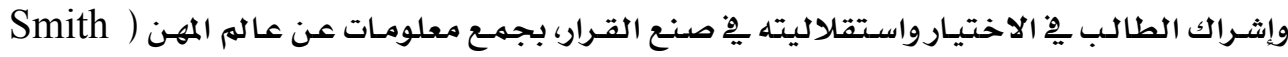

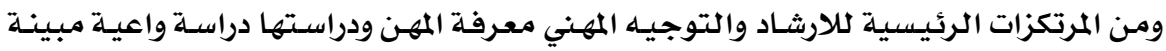

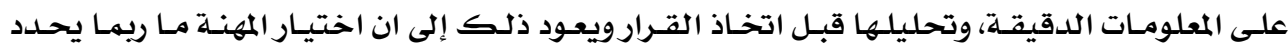

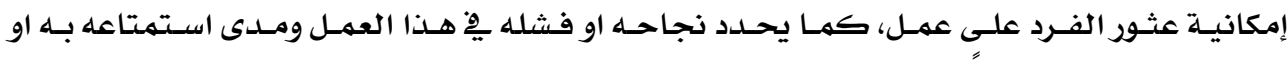

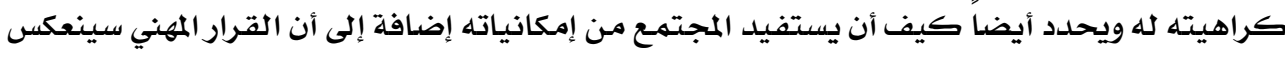
على جميع جوانب حياته (Saskatchewan,2008).

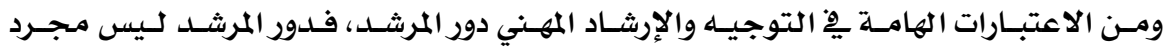

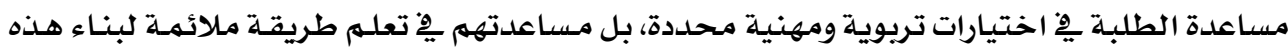

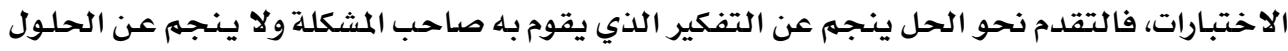

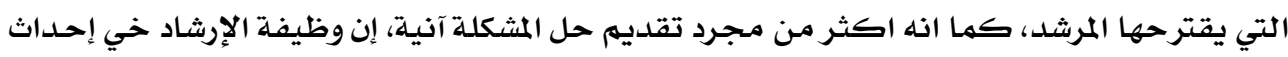


تخييرات يف الفرد تمكنه مـن اتخـاذ قرارات رشيدة (Hasan,Wagner,1996) وتحهـل مسؤولية هـذه

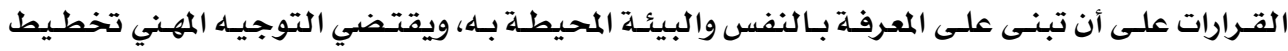

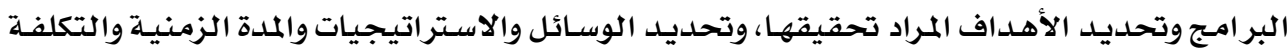

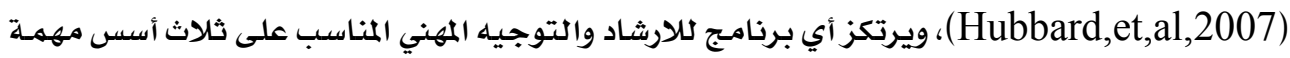

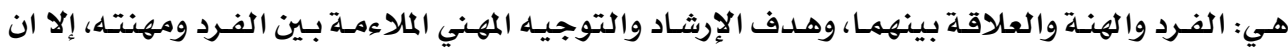

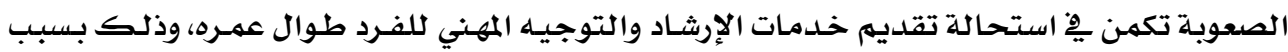

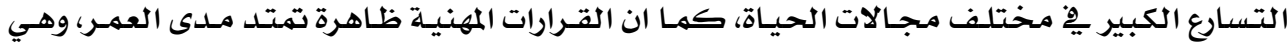

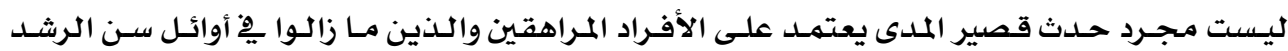

.(Pinquart,et,al,2004)

ومن العناصر الرئيسة يِّ برنامج الإرشـاد والتوجيـه المهني عملية اتخـاذ القرار، وهي عملية

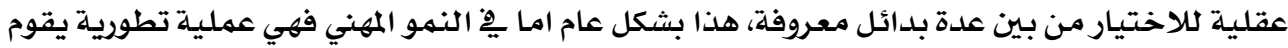

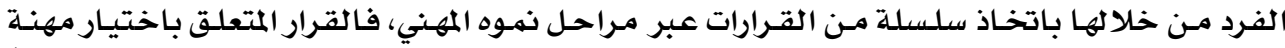

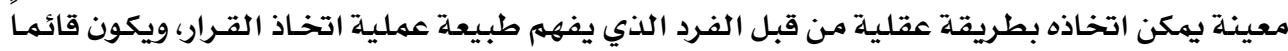

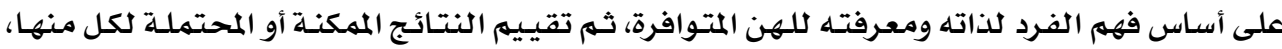

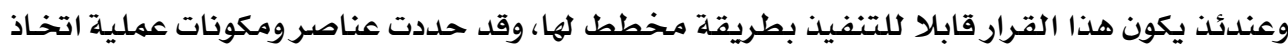

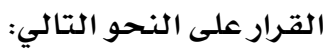

$$
\text { 1- الغرض او الهدف- تحديد الفرد لهدفه. }
$$

r- جمع المعلومات وتحليلها، ومعرفة مدى علاقتها بالفرد وعلاقتها بأهدافه.

$$
\text { r- م- وضع استراتيجية وتتضمن هذه الاستراتيجية ما يلي: }
$$

أ - تحديد البدائل الممكنة، والتنبؤ بالنتائج المترتبة عليها والنتائج المحتملة.

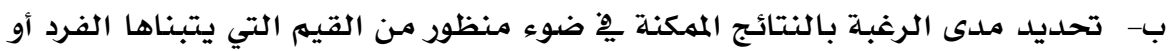

$$
\text { مصلحته. }
$$

ج- التقييم واتخاذ القرار حسب المحك او قيمة معينة (Saskatcewan,2008).

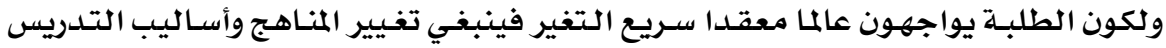

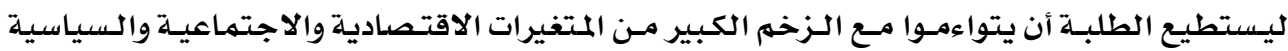

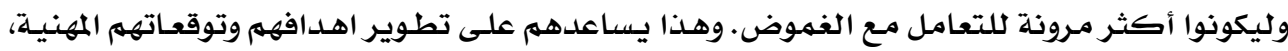

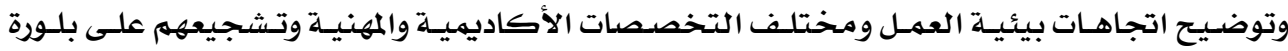

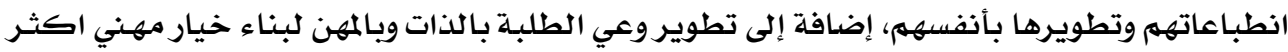

مناسبة لقدرات الطلبة وقابلياتهم ولتسهيل الانتقال إلى عالم العمل (Primozic,et,al,2008). 
ولانجـاز أهداف المنهـاج فقد طورت مواضـيع أسـاسـية عالم المهن الخـارجي ليستطيـع الطلبـة

$$
\text { التعرف بوضوح على المتطلبات والمهارات التي تحتاجها المهن. }
$$

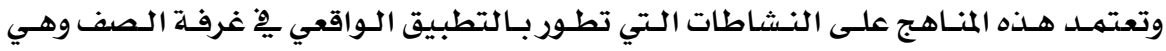

منظمة يفّ أربعة نهاذج يعكس أهداف المنهاج ويساعد المعلمون الطلبـة على تطوير معارفهم واتجاهـاتهم ومهاراتهم على اكتشاف وتطوير خياراتهم.

وتدور محاور النهماذج حول تنهية الوعي بقابليات الشخص وهواياته واهتماماته وبخصائصٍ

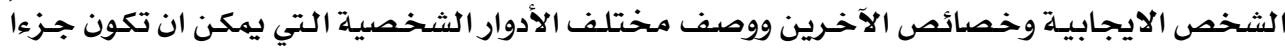

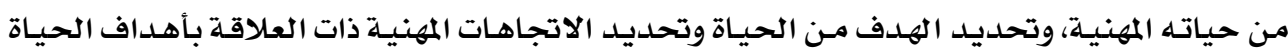

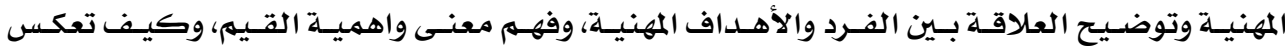
سلوكات الآخرين مشاعرهم ووصف اسلوب تطوير المفاهيم الذاتية واحترام مشاعر الآخرين. ويؤثر المعلهم مِّ البناء النفسي للطلبة، فيبني قيماً واتجاهات ويغير قناعات، ومن هذا المنطلق

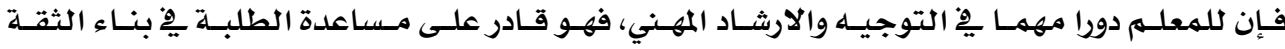

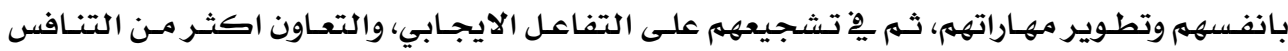

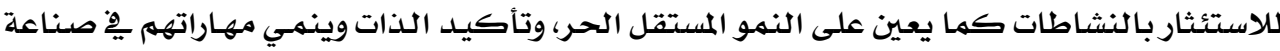
القرار وحل المشكلة ويشجعهم على التفكير الابداعي وتطوير القيهم.

وجعل التعلهم تفاعلي ذو معنى شخصي، وتشجيع المناقشة والأسئلة وتقييم القابليـات، غرس

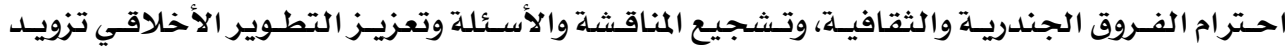

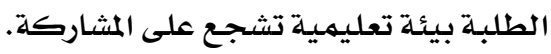

\section{أهداف التوجيه المهني:}

يمكن إجمال أهداف التوجيه والإرشاد المهني بما يلي: 1- الاهتمام بالتوجيه الفردي للطلبة الذين هم بحاجة إلى البحث والتشخيص. ץ- تزويد الطلبة المرحلة الأسساسية بأحدث المعلومات حول التخصصات الأكاديهية والمهنية تزويدهم بالمعلومـات عن المهن المطلوبة والمشبعـة والراكدة يِّه سوق العمل. r- - توجيـه الطلبة للههن حسب ميولهم وتعريفهم باستعداداتهم وقدراتهم من خلال الاستعانة بالخبر اء والمتخصصين يْ هذا المجال، ومساعدة الطلبـة على تطوير وتنهية الميول الإيجابية تجاه التخصصات التقنية والمهنية ودفعهم إلى التعلهم الذاتي المستمـر لكل جديد ِِّ الحياة وبخاصدة فميا يتعلق بسوق العمل وتطويرها اقتصادياً ومهنياً. 
ع- توعية اولياء امور الطلبة بِ نهاية المرحلة الأساسية باهمية الإعداد الأكاديمي والمهني من خلال المدرسة ومتابعة الأسرة من اجل تمكين الطلبة من حسن اختيار تخصصاتهم ومساراتهم التعليمية وبالتالي تمكينهم من اختيار المهنة المستقبلية. ه- الاهتمام بالاحصاءات والتقارير وبناء قاعدة للمعلومات للباحثين والمهتمين بالشؤون الطلابية وجمع المعلومات عن سوق العمل، والتعاون مع القطاعين العام والخاص من اجل تعريف الطلبة بواقع سوق العمل وعلاقة التخصصات بالوظائف. تعريف طلبة الصف العاشر بمسارات الدراسة ٌِِ المرحلة الثانوية ِِّ مختلف التخصصات الأكاديمية والمهنية من خلال التعاون مع المدارس الثانوية والتعريف بمتطلبات المهن

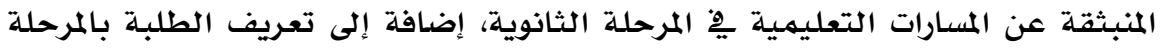
الثانوية من حيث أسلوب الدراسة وطبيعة المناهج وشروط الالتحاق بكل مسار تعليمي

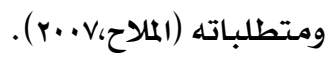
تنمية تقبل جميع انواع المهن عند الطلبة لمواءمة احتياجات المجتمع من المهن المتنوعة وإبراز اهمية كل مهنة كعنصر بارز يِّ رقي المجتمع وتقدمه. 1- تنمية قيم العمل لدى الطلبة كتحمل المسؤولية وبذل الجهد والتعاون والعمل بروح الفريق والمبادرة وتقدير احترام الوقت والانضباط يِّ العمل. 9- العمل على دعم ورعاية المبادرين والمبدعين الذين يتميزون بقدرات ومهارات ابتكارية، ولهم القدرة على المخامرة والمجازفة البناءة والمبينة على معرفة بالواقع الاقتصادي.

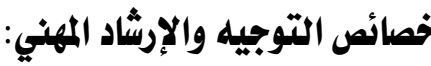

$$
\text { 1- - مراعاة الفروق الفردية بين الطلبة. }
$$

r- الشمول بحيث تشمل كافة الفئات العمرية وأولياء امور الطلبة وكافة المسارات المهنية. r- التكامل بحيث تتكامل جهود الأجهزة الإعلامية المختلفة من صحافة وإذاعة وتلفاز وقنوات

$$
\text { فضائية مع الجهود التربوية وجهود اولياء الأمور. }
$$

ع- الخصوصية إذ ينبغي ان يراعي التوجيه والارشاد المهني حالات بعض الأفراد التي تستدعي

$$
\text { الخصوصية. }
$$

ه- التطبيق الأصل ِِِ برامج التوجيه المهني أنها عملية تطبيقية لا تكتفي بالجانب التنظيري.

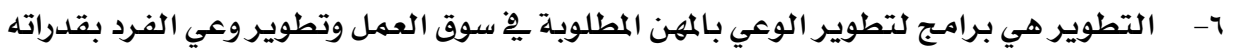




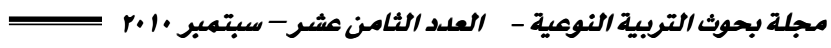

V- المرونة وهي برامج تطور ذاتها حسب البيئة ومتطلباتها البيئة البشرية والمادية وحاجات

السوق.

1- الاحتر اف التوجيه المهني بحاجة لدرجة عالية من التخصصية والاحتر اف للتأثير بالفئة.

\section{وظائف التوجيه والارشاد:}

ا- الوظيفة البنائية الانمائية: وتتمثل ِِّ إثراء معرفة الطالب بنفسه والعالم المحيط بـه

واكتساب مهارات السلوك الاجتماعي وتطوير اتجاهات إيجابية نحو ذاته ونحو الاخرين

ونحو المهن.

ץ- - الوظيفة الوقائية: وتشمل تنمية إمكانات الطالب بهدف اجتناب الوقوع ِِ المشكلات وتطوير قدراته على التعامل مـع المواقف المختلفة كما انها محاولة للكشف المبكر عن الاضطراب ِِّ مرحلته الأولى بقصد السيطرة عليه ومنـع تطوره. r- - الوظيفة العلاجية: وتتضمن المساعدة الفنية للطالب لحل مشكلاته ومساعدته على التكيف وتحقيق التوازن النمائي لديه بحيث يكتسب القدرة على توجيه ذاته والتغلب على صعوباته بنفسه يف المستقبل (عثامنـه، +.r).

\section{الصعوبات والتحديات التي تواجه التوجيه والإرشاد المهني:}

ويعتبر تحديد أهم الصعوبات والتحديات فِّ مجال التوجيه والإرثاد ضرورة لمواجهتها وإيجاد حلول لها ويْ هذا السياق يهكن تحديد أهم هذه الصعوبات والتحديات فيما يلي: ا- التحدي التكنولوجي المعلوماتي: الناتج عن المتغيرات المستهمرة يْ بناء المهن نتيجة التطور

$$
\text { التكنولوجي المتسسارع: }
$$

ץ- البطالة: يِّ ظل الهزات العنيفة التي يشهدها سوق العمل التقليدي بفعل ثورة المعلومات

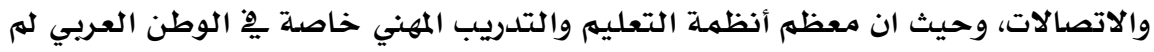

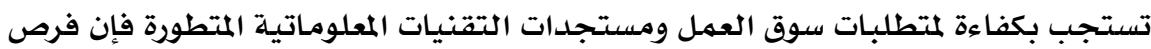
تشغيل الخريجين ستكون اكثر محدودية، وهذه لا تخص الوطن العربي وحدها بل بل تتعداه لتشمل معظم دول العالم. ب- تحديات الإصلاح الهيكلي: تشكل إجراءات الإصلاح الهيكلي للاقتصادات وخاصلة يِّ الدول

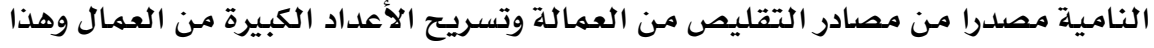

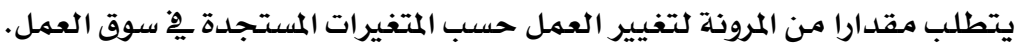

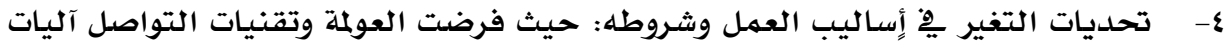

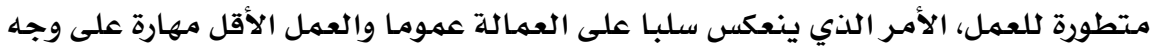

$$
\text { الخصوص (الدويبي،ه. - مب). }
$$




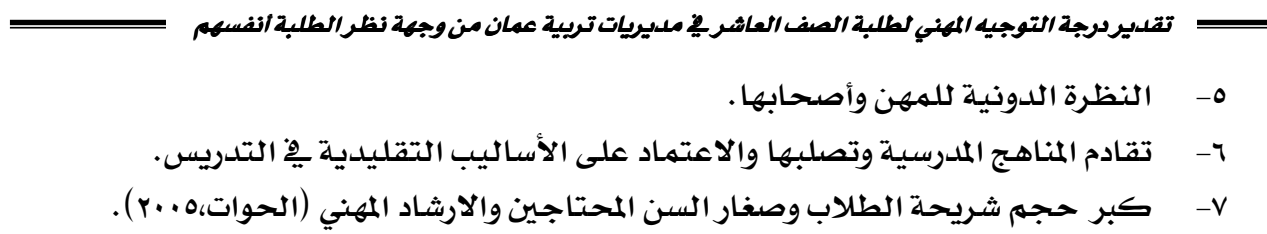

\section{نبذه عن أنظمة التوجيه والإرشاد المهني العالمية:}

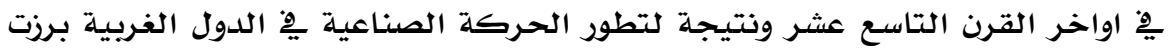

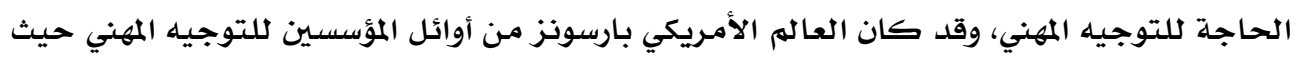

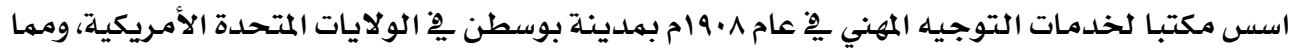

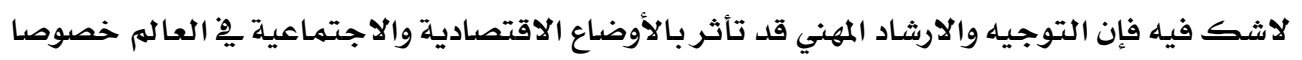

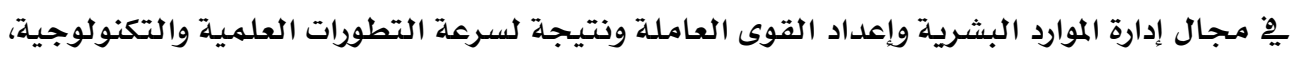

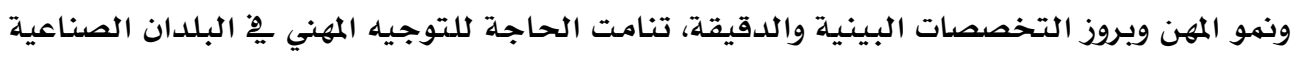

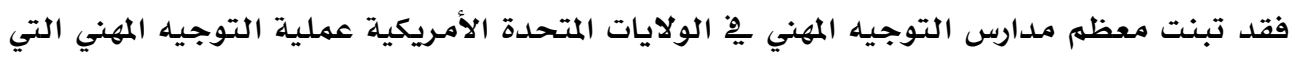

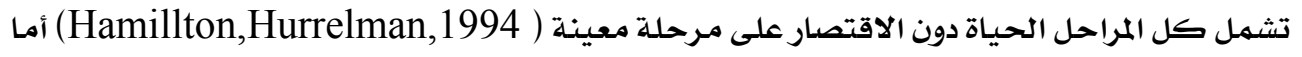

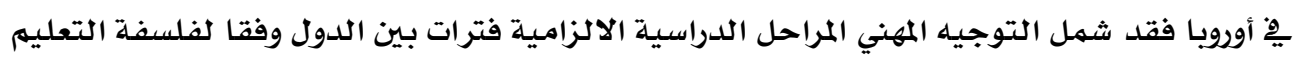

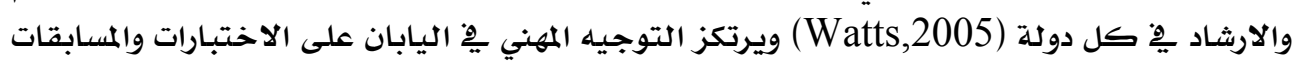

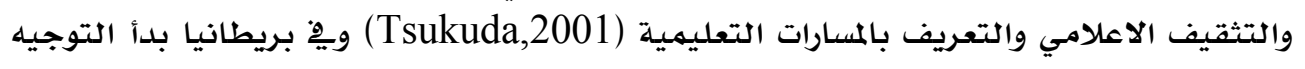

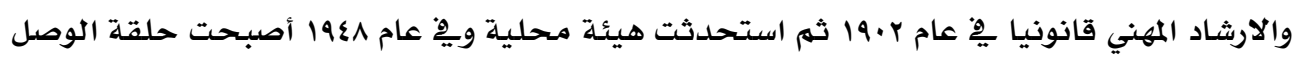

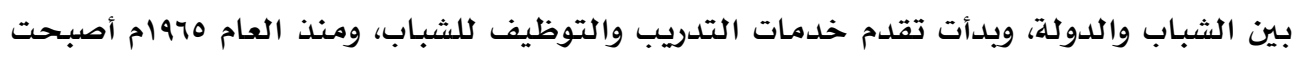

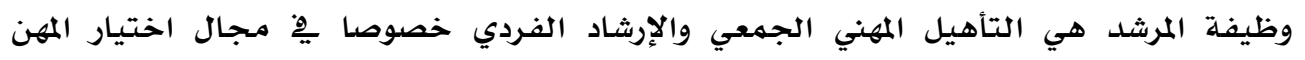

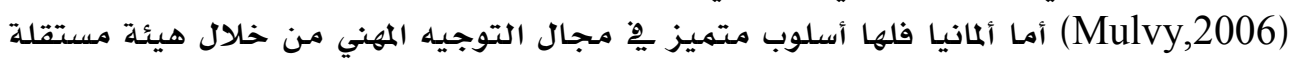

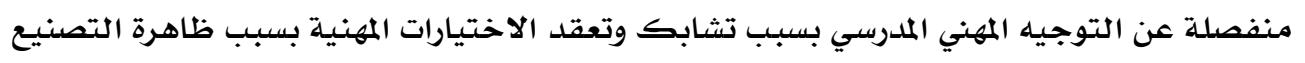

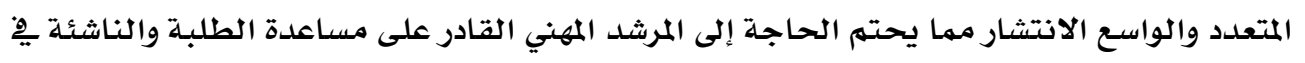

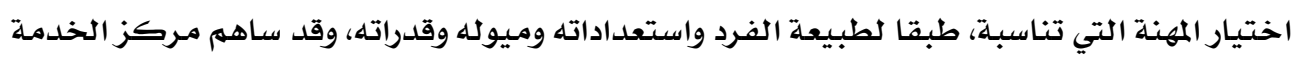

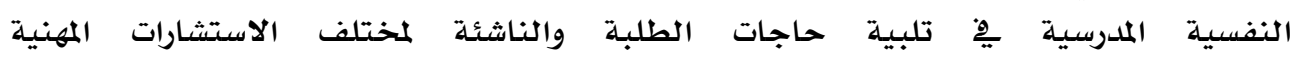
(Pinquart,et.al,2004)

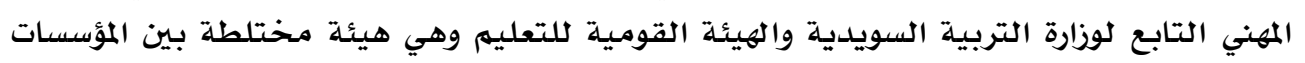

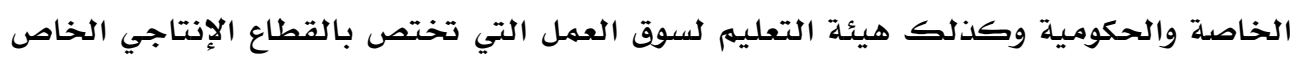

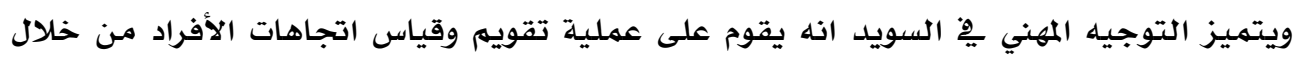
الاختبارات والمقاييس المهنية (Guidance \& Counseling in Swedan,2006) امـا نشاط التهاط

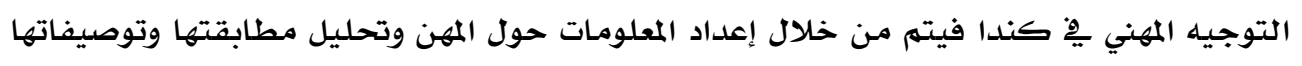

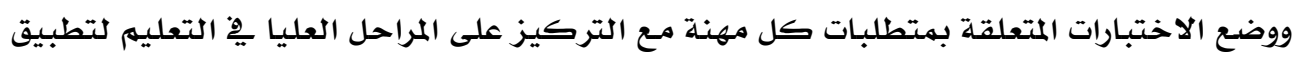

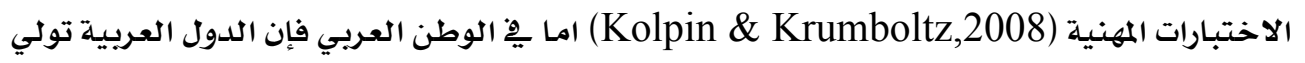

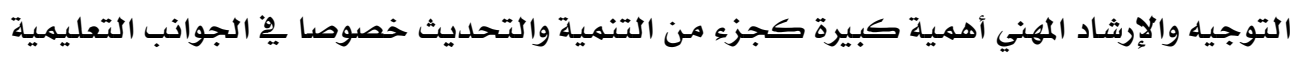




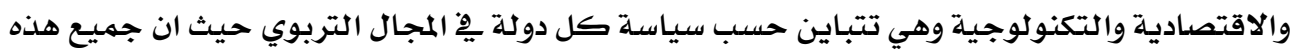

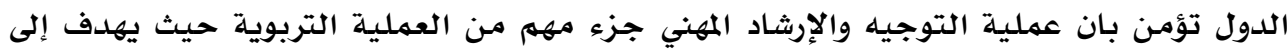

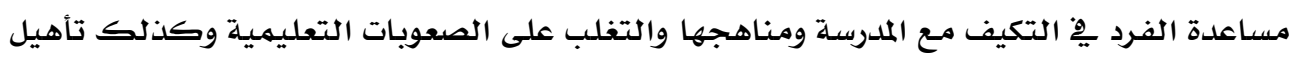

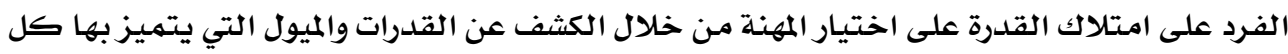

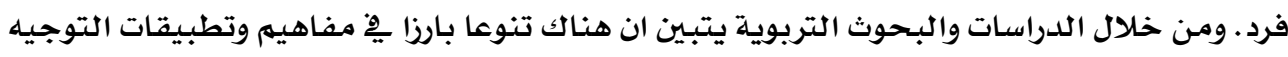

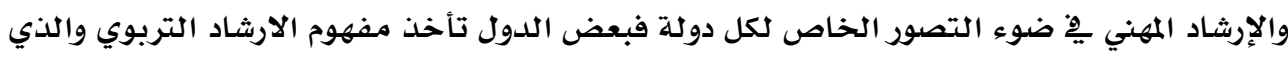

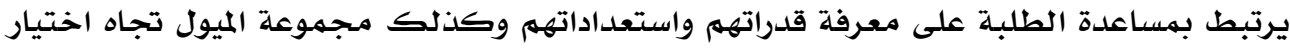

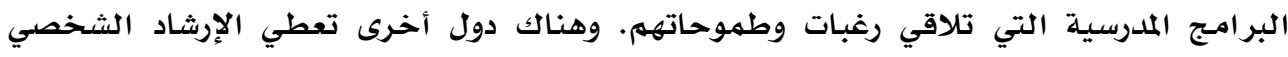

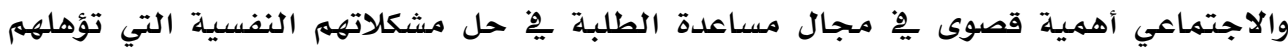

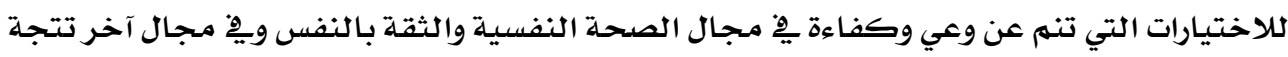

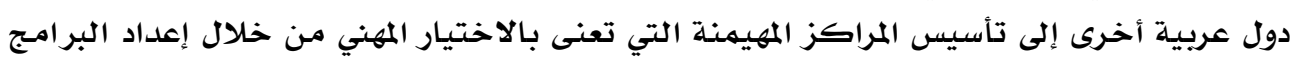

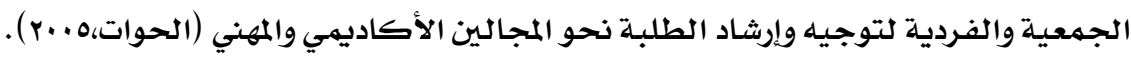

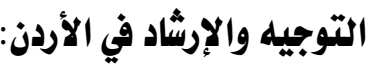

بدأت الخدمة الإرشادية تدخل مدارس المملكة عند تغيير نظام التعليم الثانوي والذي تبعهـ

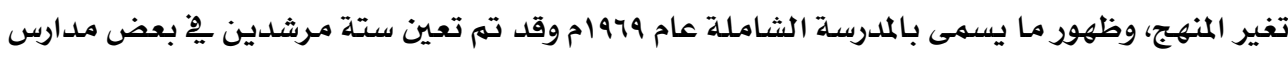

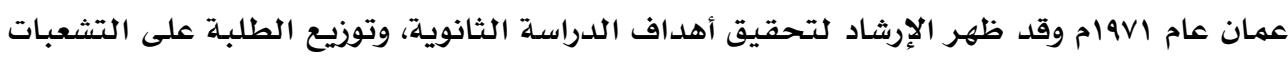
التي تتناسب وقدرتهم التحصيلية، وذلك من خلال تحقيق الأهداف الفرعية التالية:

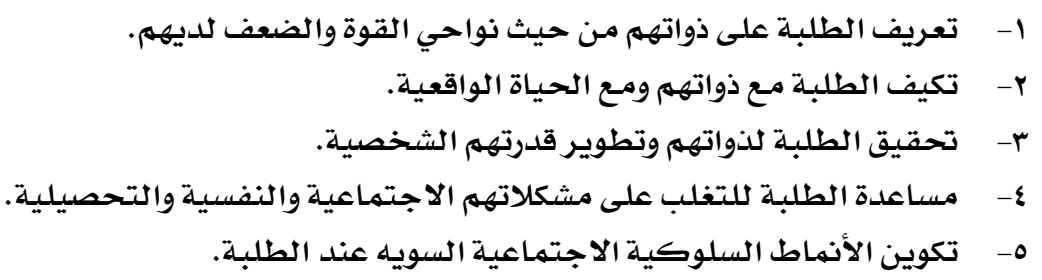




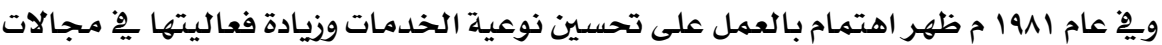

الرشاد النفسي الاجتماعي وشؤون الطلبة التعليمية السلوكية.

ويٌْ عام rه/ام اجريت دراسة ميدانية تقيمية وضحت الدور الإيجابي للإرشاد على الطلبة،

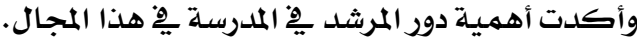

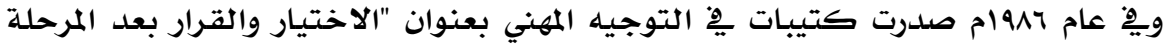

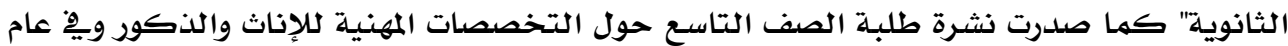

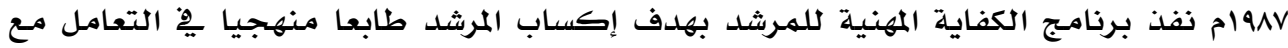

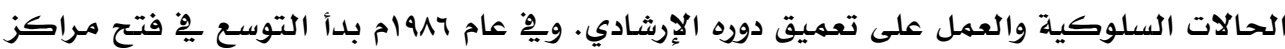

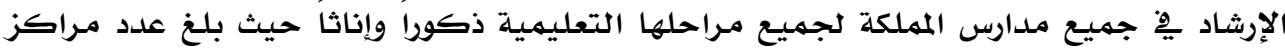

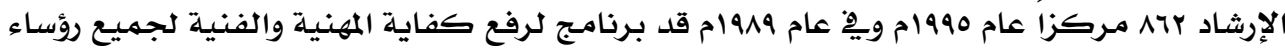

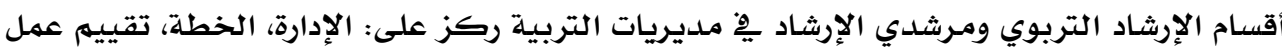
المرشد التربوي وتحليل الكفايات المهنية لعمل المرشد.

وعقدت دورة إقليمية يِّ التوجيه المهني للفتيات والنساء شارك فيها خبراء من الدول العربية والمؤسسات التربوية المختلفة فِِ الأردن.

واصبحت طموحات قسم الإرشاد تتركز فيما يلي:

تطوير برنامج مهني هٍِ المدارس، إنشاء مركز متخصص للإِرشاد التربوي والمهني، إعداد

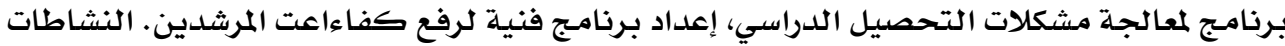

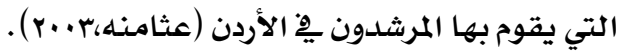

الدراسات السابقة: - ابة

يستعرض هذا الجزء من البحث الدراسات السابقة التي تناولت التوجيه والإرشاد وسوق المارق

العمل ذات العلاقة المباشرة بالموضوع المبحوث.

فقد أجرى أوزديمير وهاكفزليغلو (Ozdemir,Hacifazlioglu,2008) دراسة هدفت إلى

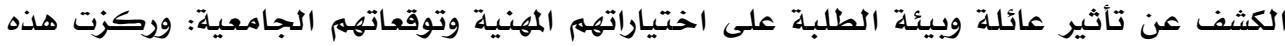

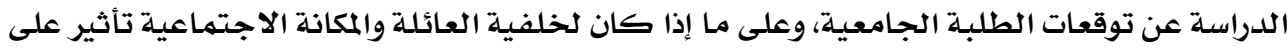

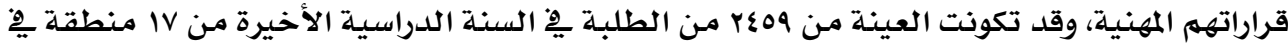

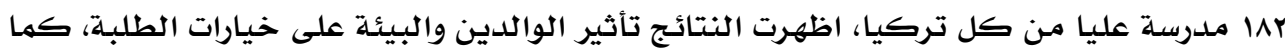
أظهرت أن توقعات الطلبة الجامعية تختلف تبعا للمكانة الاجتماعية ولدخل الأسرة ولتأثيرات التئل 
أجرى جونسون وكوب (Johnson \& Chope,2005) دراسة هدفت إلى معرفة مباديء

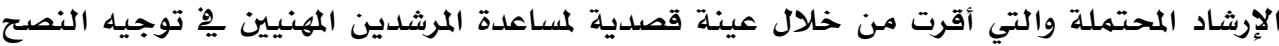

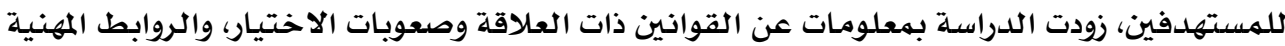

التي يجب أن تطور، وقد وجهت قائمة من الأسئلة للمستهدفين لمساعدتهم على اتخاذ القرار المهات المهني.

أجرت هلمان (Hellman,2004) دراسة هدفت إلى الكثف عن مراحل التطوير المهني مِّ2

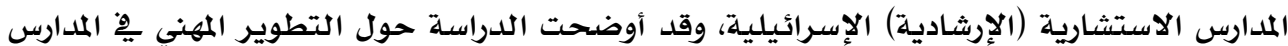

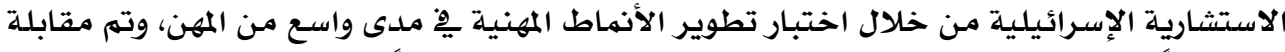

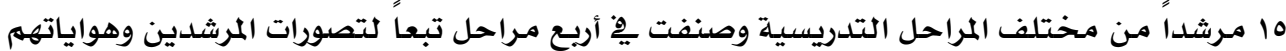

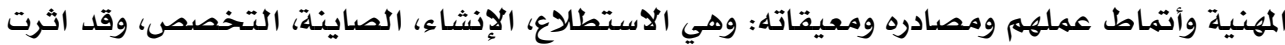

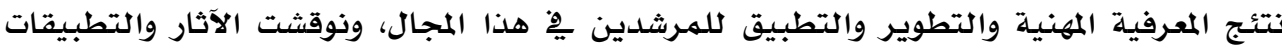
العملية للإشراف والتخطيط.

أجرى مبارك (ץ...r) دراسة هدفت إلى اختبار أثر برنامج تدريبي مِّْ الإرشاد والتوجيه

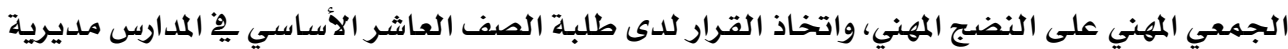

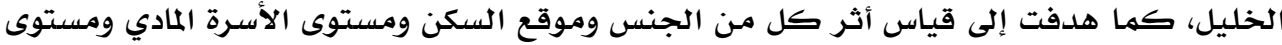

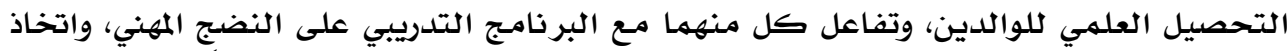

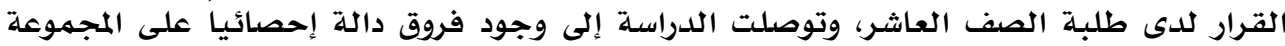

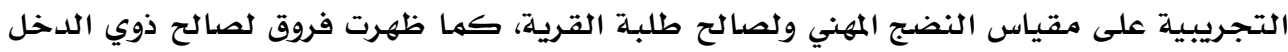

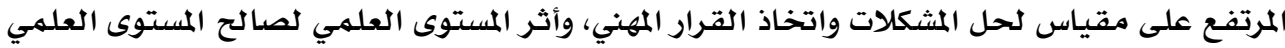
للأدب على مقياس النضج، ومستوى الام العلمي على مقياس اتخاذ القرار، وأثرت مهنة الأب التراي كموظف عمل الأم على مقياس النضج. أجرى بايل وواندا (Pyle,Wanda,1998) دراسة هدفت إلى الكثف عن اثر الفرص المهنية

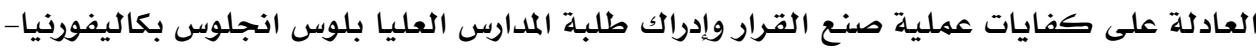

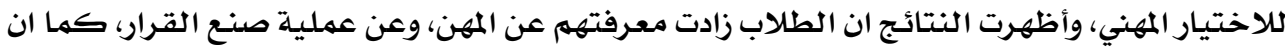

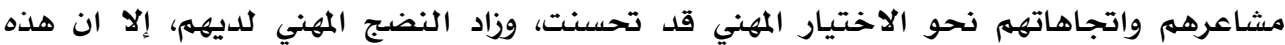

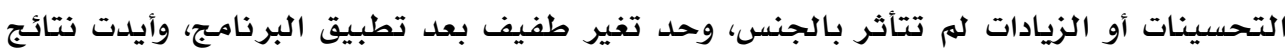

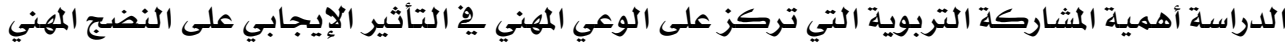
لديهم. وقام الخصاونة وآخرون (1991) بدراسة هدفت إلى التعرف على حجم البطالة وخصائصها

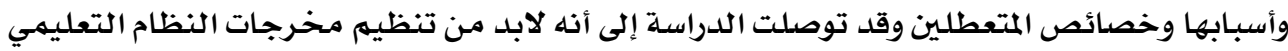

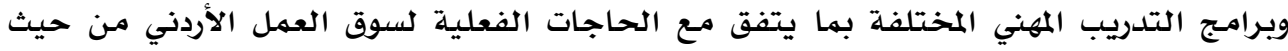

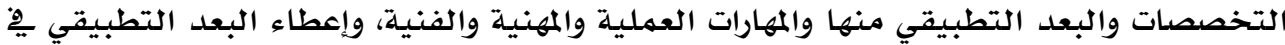




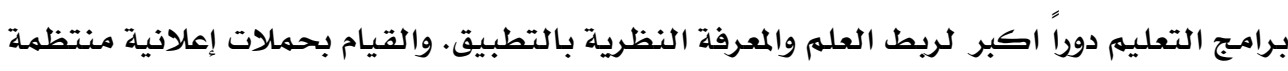

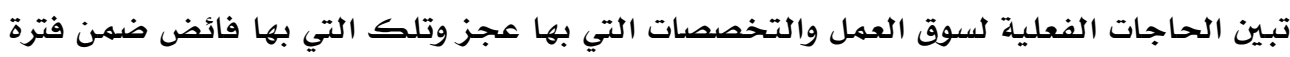

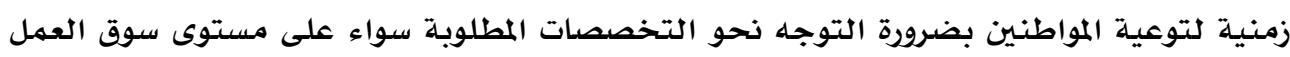
المحلي او العربي. زتوعية المواطن

أجرى الخرابشة (1999) دراسة هدفت إلى تحليل الآثار الاقتصادية للاستثمار بِّْ رأس المال

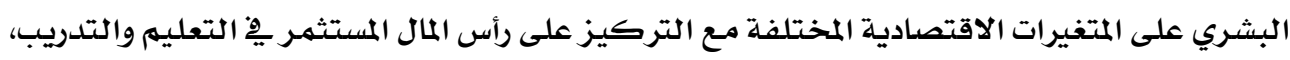

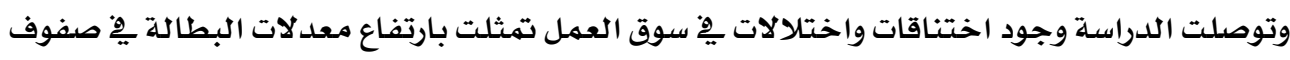

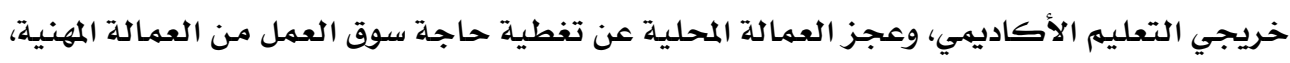

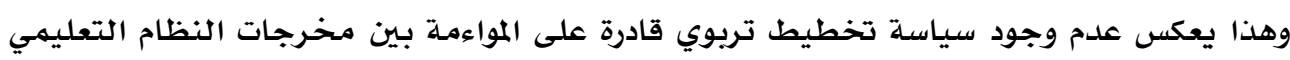

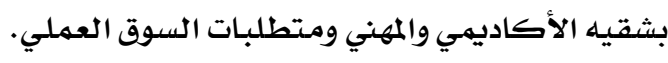

اجرى الداود (1997) دراسة هدفت إلى اختبار أثر برنامج تدريبي مِّ الإرشاد والتوجيه

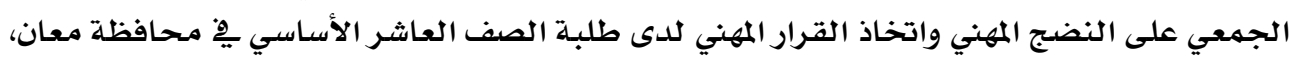

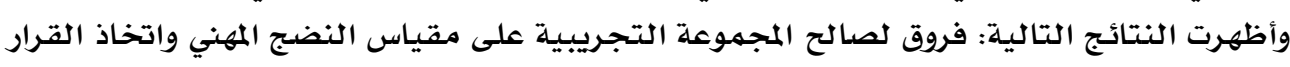
وحل المشكلات.

أجرى جعنيني (1999) دراسة هدفت إلى تعرف اتجاهات طلبة الصف العاشئ العاشر الأساسي

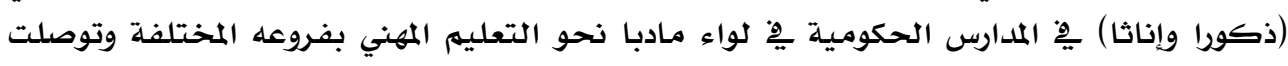

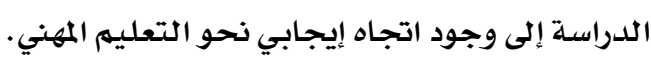

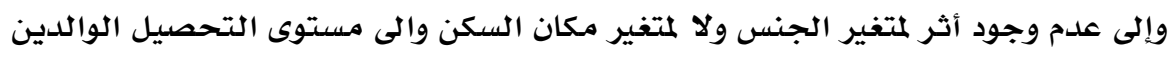

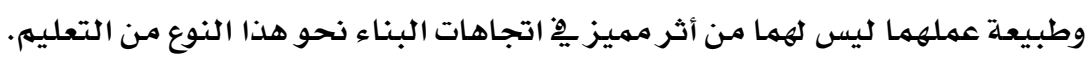

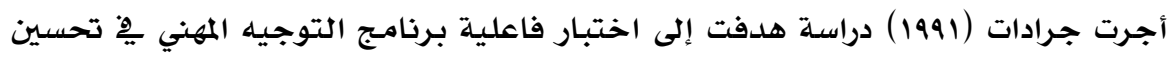

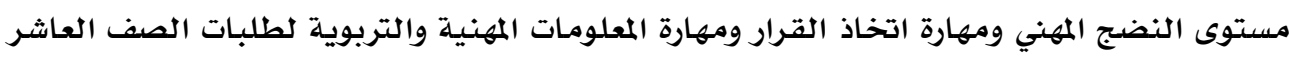

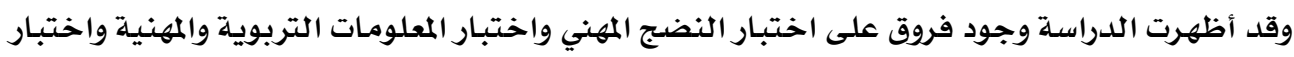
حل المشكلات.

وأجرى الصمادى (1914) دراسة هدفت إلى معرفة العلاقة بين توجيهات الوالدين، ونضيج

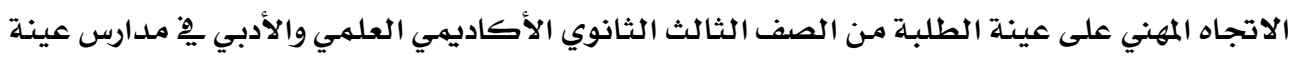

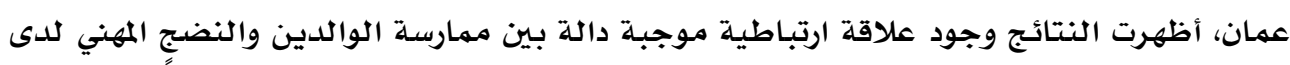

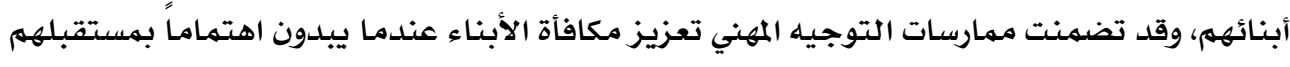

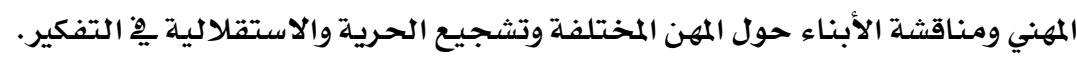

أجرت الفياض (19AV) دراسة هدفت إلى ممعرفة أثر التنشئة الأسرية على اتخاذ القرار

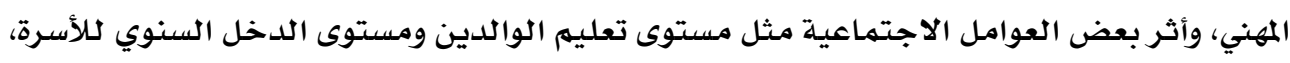




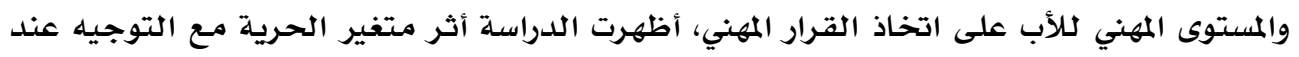

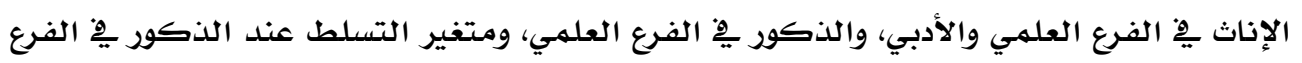

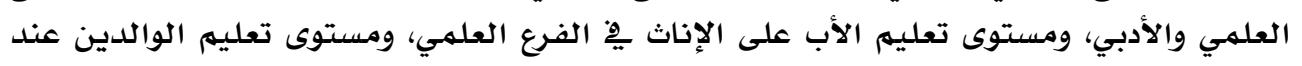

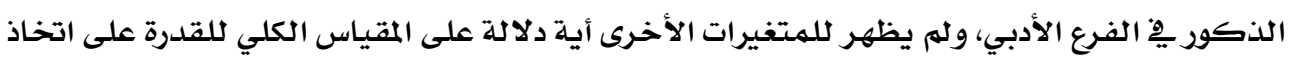
القرار المهني.

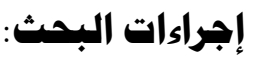

يتناول هذا الفصل من البحث وصف لمجتمع البحث وعينته وتحديدها، والإندات وكيفية اختيارها

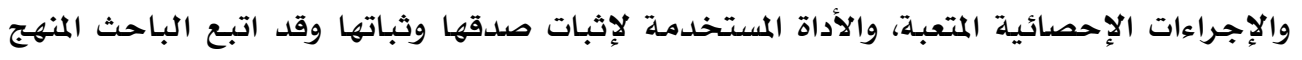

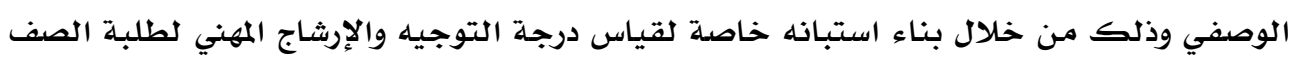

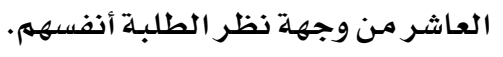
هبتهمع البمث:

تكون مجتمع البحث من جميع طلبة الصف العاشر بِّ مديريات تربية عمان الأربعة والبالغ

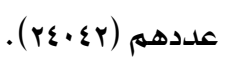

\section{عينة الدراسة:}

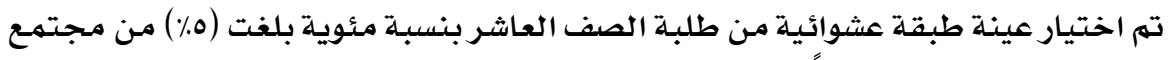

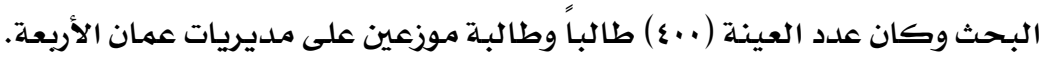

جدول رقم (1) التكرارات والنسب المئوية لعينة الدراسة حسب المتغيرات المستقلة

\begin{tabular}{|c|c|c|c|}
\hline النسبة & التكرار & الفئات & المتغير \\
\hline$\varepsilon 0, r$ & $|\wedge|$ & ذ ذكر & \multirow{2}{*}{ 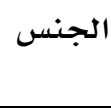 } \\
\hline $0 \xi, \Lambda$ & r19 & 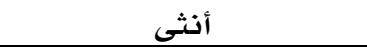 & \\
\hline $0 \wedge, r$ & 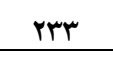 & أقل من ·0ب & \multirow[t]{3}{*}{ 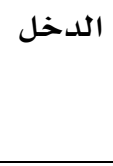 } \\
\hline$r r, 0$ & $\varepsilon 9$ & من (v. (v. (v) & \\
\hline$M, r$ & $v_{r}$ & أكثر من · V V & \\
\hline rr.. & $9 r$ & مديريـة تربية عمان الأولى & \multirow[t]{4}{*}{ المديريـة } \\
\hline ro. & $1 \cdots$ & مديريـة تربيـة عمـان الثانية & \\
\hline r,$\Lambda$ & $1 \cdot \mathrm{V}$ & مديريـة تربية عمـان الثالثة & \\
\hline Yo,r & 1.1 & مديريـة تربيـة عمان الرابعـة & \\
\hline $1 \ldots, \cdot$ & $\varepsilon \ldots$ & \multicolumn{2}{|l|}{ المجموع } \\
\hline
\end{tabular}




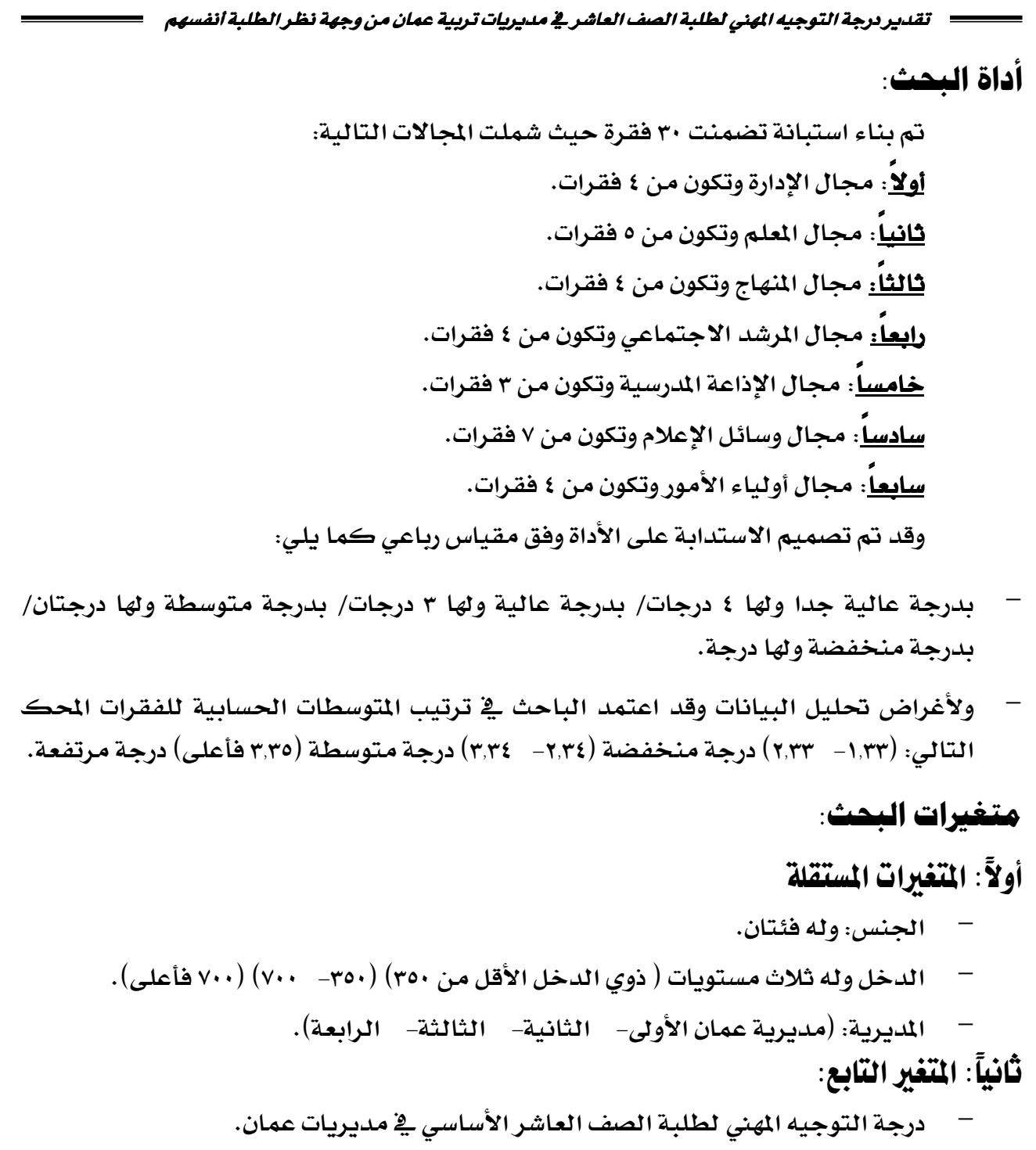

* صدق الأداة وثباتها:

تم التحقق من صدق الأداة بعرضها على محكمين متخصصين وقد أشار بعضهم بتعديل

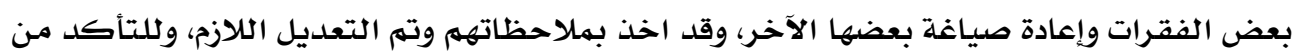

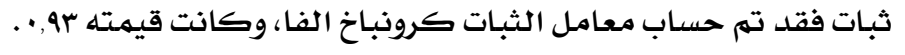




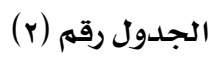

بين معامل الاتساق الداخلي كرونباخ ألفا للمجالات للأداة ككل

\begin{tabular}{|c|c|}
\hline الاتساق الداخلي & المجال \\
\hline - מ & الكلي \\
\hline
\end{tabular}

المالجة الإحصائية:

بعد التأكد مـ صدق الأداة وثباتها وتحديد مجتمـع الدراسة وعينتها، تم توزيع الاستبـانة

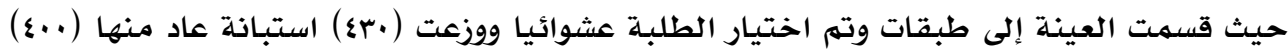

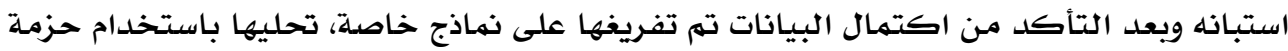

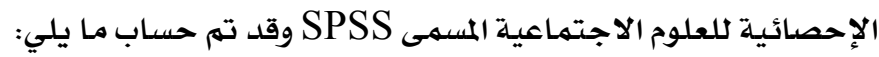

ا- الإحصاء الوصفي: إذ تم استخراج المتوسطات الحسابية والانحرافات المعيارية لمجالات

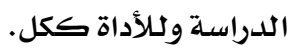

ץ- - الإحصاء الاستدلالي: إذ تم حساب تحليل التباين الثلاثي وأجريت المقارنات البعيدة باستخدام اختبار شيفيه للكشف عن مصدر التباءين.

\section{النتائج وهناقشتهها:}

يعرض هذا الجزء من البحث نتائج التي تم التوصل إليها من خلال إجابة أفراد عينة

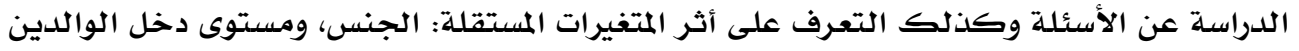
سنوات الخبرة، المديرية على درجة طلبة الصف العاشر للتوجيه المعنوي إليهم للإجابة عن السؤال الأول: مـا درجة التوجيه المهني لطلبة الصف العاشر ِِّ مديريات تربية عمان من وجهة نظر الطلبـة انفسهم. 
والجدول رقم (r)

يبين المتوسطات الحسابية والانحرافات المعيارية لمجالات الدراسة مرتبة تنازليا حسب المتوسطات

\begin{tabular}{|c|c|c|c|c|c|}
\hline الدرجة & الانحراف & المستوسط الحسبي & المجال & رقم & الرتبة \\
\hline مرتفعة &., 91 & r.,. & المرثد الاجتماعي & $\varepsilon$ & 1 \\
\hline متوسطة & $\cdot, \mathrm{VA}$ & $r, Y T$ & وسائل الإعلام & 7 & $r$ \\
\hline متوسطة & $\cdot, \wedge \cdot$ & r.r. & المعلم & $r$ & $r$ \\
\hline متوسطة & •,AY & r.v. & المنهاج & $r$ & $\varepsilon$ \\
\hline متوسطة & $\cdot, \Lambda 1$ & Y.৭r & أوكياء الأمور & $v$ & - \\
\hline متوسطة & $\cdot, \mathrm{vr}$ & Y,\&r & الإدارة المدروسية & 1 & 7 \\
\hline منخفضة & $\cdot, \wedge 9$ & $r, \cdot \bullet$ & الإذاعة المدرسية & ○ & $v$ \\
\hline & $\cdot, 7 v$ & $r, \cdots$ & \multicolumn{3}{|c|}{ الأداة ككل } \\
\hline
\end{tabular}

تم استخراج المتوسطات الحسابية وانحرافاتها المعياريـة لأداة الدراسـة ومجالاتها وفقراتها. وقد بلغ المتوسط الحسابي ككل (r) وبانحراف معياري قدره (TV,·) وحصل مجال (المرثد

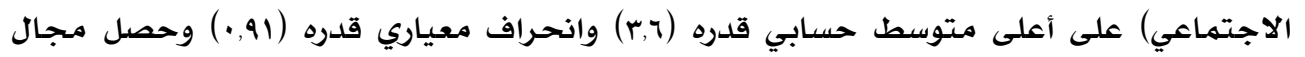

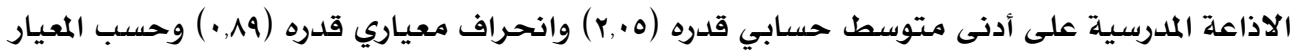

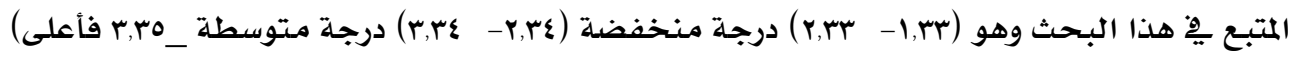

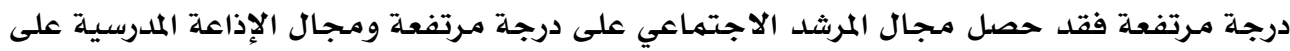

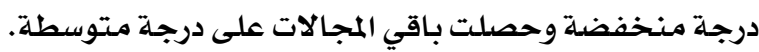
وذلك أن من مهام المرثد الاجتماعي توعية الطلبـة بواقع المهن ومستقبلها لمساعدتهم لاختيار التي تناسب قدراتهم وميولهم وذلك عن طريق عرض أفلام وثائقية تبـين أهمية المهن وتنظيم المها

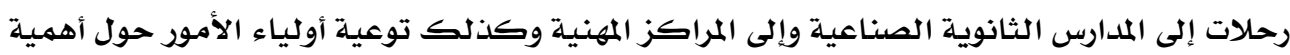

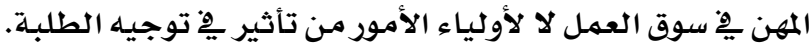




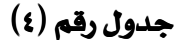

يبين المتوسطات الحسابية والانحرافات المعيارية لفقرات المجال الرابع مرتبة تنازليا حسب المتوسطات الحسابية

\begin{tabular}{|c|c|c|c|c|}
\hline الانحراف & المتوسط الحسابي & الفقرات (مجال المرشد الاجتماعي) & 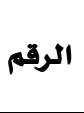 & الرتبة \\
\hline $1, r_{1}$ & $r, \Lambda \cdot$ & 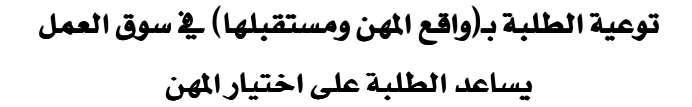 & 1 & 1 \\
\hline $1 . \cdot 7$ & r,vo & عرض أفلاماً وثائقية تبين أهمية المهن & $r$ & $r$ \\
\hline 1,11 & r,,$\varepsilon \varepsilon$ & تنظيم رحلات إلى المدارس (الثانوية الصناعية/ المراكز & $r$ & $r$ \\
\hline $1, \cdot v$ & $r, \varepsilon)$ & تنظيم لقاءات توعية لأولياء امور الطلبة حول اهمية المهن & $\varepsilon$ & $\varepsilon$ \\
\hline
\end{tabular}

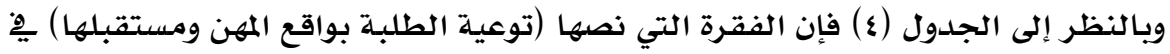

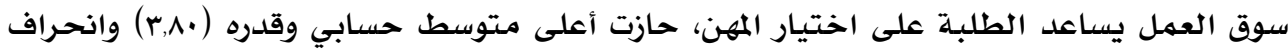

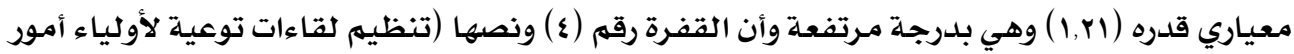

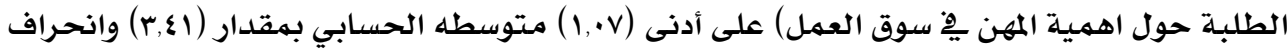

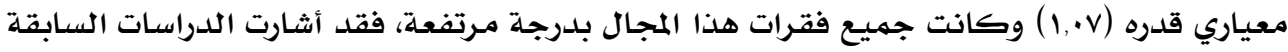

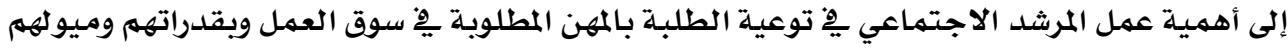

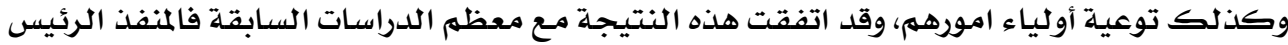

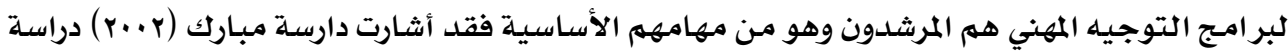

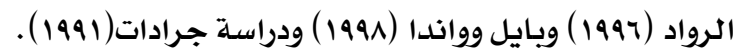
إلى أثر البرنامـج التدريبي الذي طبقه المرشد التربوي على نضج الطلبـة المهني وقدرتهم على 
جدول رقم (0)

يبين المتوسطات الحسابية والانحرافات المعيارية لفقرات المجال السادس مرتبة تنازلياً حسب المتوسطات

الحسابية

\begin{tabular}{|c|c|c|c|c|}
\hline الانحراف & المتوسط & الفقرات (مجال الإعلام) & رقم & الرتبة - ال \\
\hline $1, \cdot 9$ & r.,09 & التركيز على البر امجج الوثائقية التي تعرض بطالة خريجي التعليه العالي تحث الطلبة على التوجيه المهني & $\varepsilon$ & 1 \\
\hline 1,17 & r,ov & البر امـج الوثائقيـة تظهر إيجابيات المهن & r & r \\
\hline $1, \cdot 1$ & r.or & البر امـج التلفزيونية التي تبين حاجـات سوق العمل الفعلية & r & r \\
\hline 1,11 & $r, r v$ & إبراز دور اصحاب المهن يِ التنمية الاقتصادية & 7 & $\varepsilon$ \\
\hline $1,1 \mathrm{r}$ & r,Y & إعلان احصائيات حول واقع سوق العمل & 1 & $\bullet$ \\
\hline I,YY & $r, r \cdot$ & إبراز المسلسـلات التلفزيونية لأصحاب المهن بصورة محببـة & ○ & 7 \\
\hline 1,10 & r,rur & توزيـع نشرات دورية ِِِ الصحف اليومية والأسبوعية توعية & $v$ & $\checkmark$ \\
\hline
\end{tabular}

يبين الجدول رقم (ه) ان الفقرة رقم (ع) حازت على أعلى متوسط حسابي قدره (r.or)

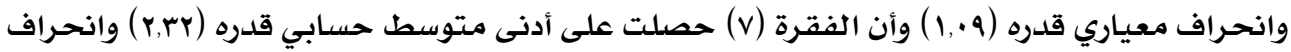

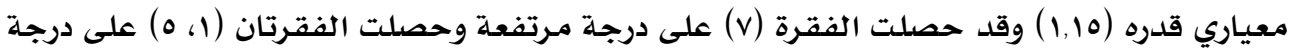

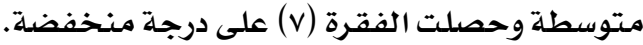

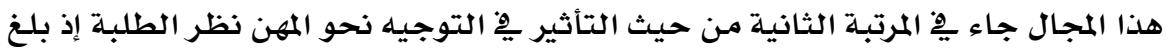

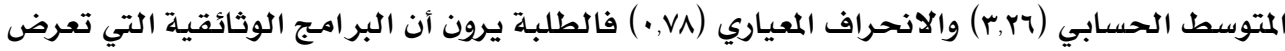

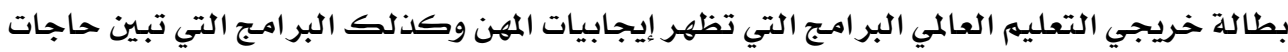
السوق العمل الفعلية والمتوقعة البر امج التي تبرز دور أصحاب المهن يِّ التنمية، وإعلان إحصائيات

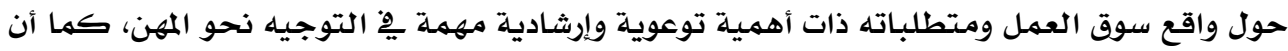

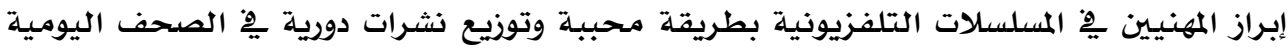
والأسبوعية كل ذلك يحثهم على التوجيه المهني ويعمل على توسيع آفاقهم الفكرية والنفسية

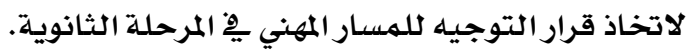

ويعزى كون وسائل الإعلام حصلت على المتوسط الثاني إلى أثر وسـائل الإعلام العميق يِّاتِ تشكيل العقول وبناء القناعات، وتغيير الآراء خاصة إذا عرضت فِّ سياق مؤثر عاطفياً فالقناعات لا 
ترستخ إلا إذا استثيرت عواطف الحب والكراهية يِ نفوس الفئة المستهدفة وأكدت دراسة خصاونة وآخرون 1991 والخرابشـه 1999 على ضرورة القيام بحملات إعلانية منظمة تبين الحاجـات الفعلية

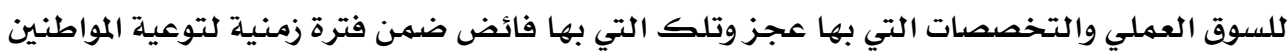
بضرورة التوجيه نحو التخصصات المطلوبـة سواء على مستوى العمل المحلي او العربي.

\section{جدول رقم (7)}

يبين المتوسطات الحسابية والانحرافات المعيارية لفقرات المجال الثاني مرتبة تنازلياً حسب المتوسطات الحسابية

\begin{tabular}{|c|c|c|c|c|}
\hline الانحراف & المتوسط الحسابي & الفقرات (مجال المعلم) & الرقم & الرتبة \\
\hline 1,17 & $r, r V$ & يحبب الطلبـة بالمهن & $\varepsilon$ & 1 \\
\hline $1, r \varepsilon$ & r,rr & يبين اهميـة المهن يِّ سوق العهل المحلي/ العربي & r & r \\
\hline $1, \cdot 0$ & r,r. & يضرب امثلة توضيحية من المهن تحفيزا لاختيار & $r$ & $r$ \\
\hline 1,11 & r,ו & ينمي المعلهم المهارات العملية لدى الطلبـة & 1 & $\varepsilon$ \\
\hline $1, Y \cdot$ & r,ir & يوضـح الطلبـة أهمية امتلاكك المرونة لتغيير & 0 & 0 \\
\hline
\end{tabular}

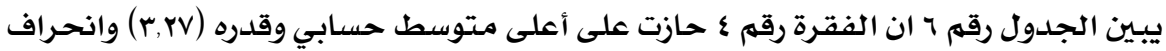

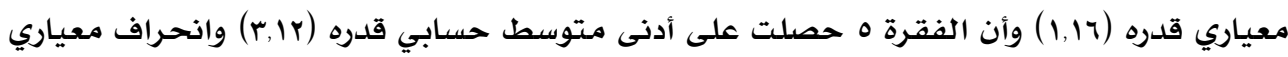

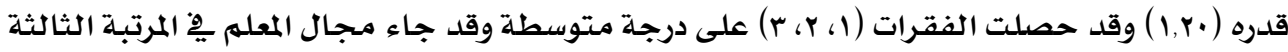

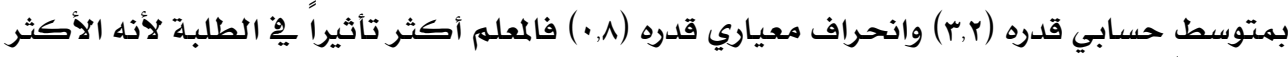

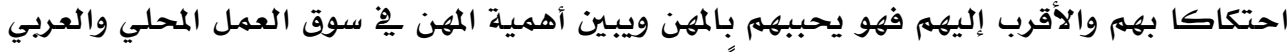

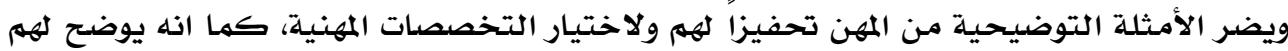
أهمية امتلاك المرونة لتغيير تخصصاتهم إذا اقتضى الأمـر وينهى لديهم المهارات العملية وهذا دور

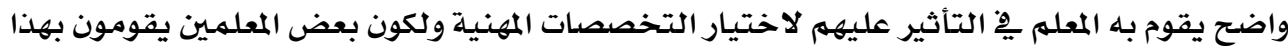

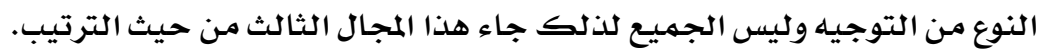

فقد أكد الأدب النظري وخاصدة ِِ تقرير صادر عام ^• Career ) تحت عنوان Guidance.Acurriculum guidance for middle level- introduction المحوري يِّ بناء جسور الثقه بينه وبين الطلبة مما يجعلهم اكثر تقبلا لأفكاره التي تتعلق بضرورة فهم الذات والوعي بقدرات الفرد وقابلياته وضرورة توجيهها واستثمارها نحو اختيار المهنة الأمثل، وامتلاكك المهارة الفكرية والنفسية لتغيير التخصص لتصد إذا اقتضى الأمر 
جدول رقم V

يبين المتوسطات الحسابية والانحرافات المعيارية لفقرات المجال الثالث مرتبة تنازلياً حسب المتوسطات الحسابية

\begin{tabular}{|c|c|c|c|c|}
\hline الانحراف & المتوسط & الفقرات (مجال المنهج) & الرقم - الم & 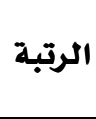 \\
\hline $1, \varepsilon$. & $r, \mathrm{rV}$ & التركيز يِّ مادة التربية المهنية على الجـانب & $\varepsilon$ & 1 \\
\hline $1, \cdot 1$ & $r, 1$. & المنهاج المدرسي يحث على العمل المهني & 1 & r \\
\hline $1, r \cdot$ & $r \cdot r$ & احتواء المنهاج على الجـانب العملي إضـافة للنظري & r & r \\
\hline 1,17 & $r, r V$ & اشتراك جميع المواد المدرسية بغرس قيمـة العمل المهني & r & $\varepsilon$ \\
\hline
\end{tabular}

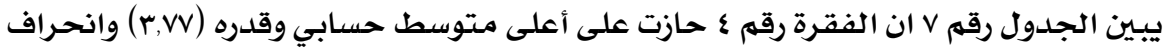

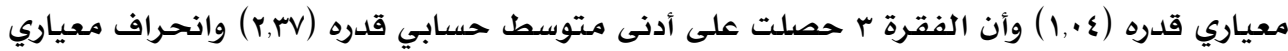

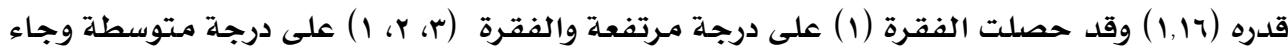

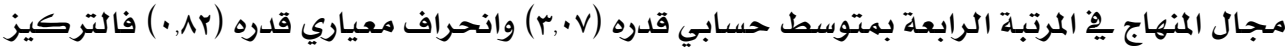

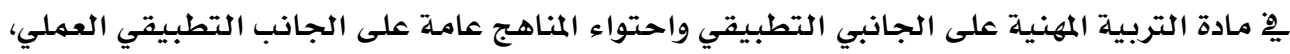

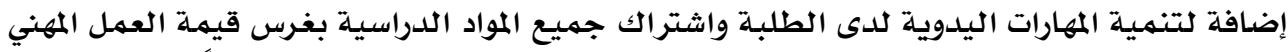

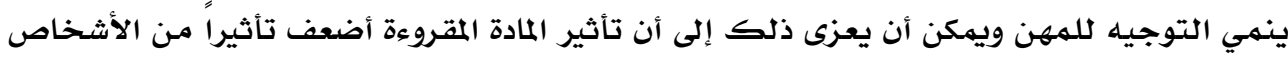

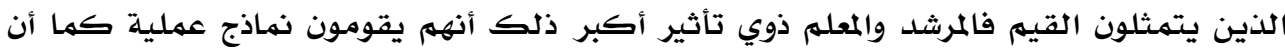

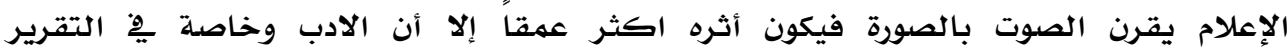

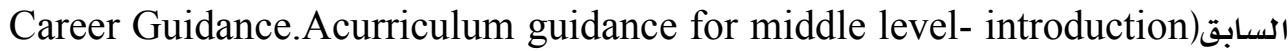
أكد أهمية المناهد يِّ تعريف الطلبـة بالمتطلبـات والمهارات التي تحتاجها المهن.

وعلى أهمية المنهاج ِِّ تنميلة الوعي بقابليات الشخص وهواياته واهتماماته وبخصائص الشخص الايجابية وخصائص الآخرين ووصف مختلف الأدوار الشخصية التي يهكن أن تكون جزياً

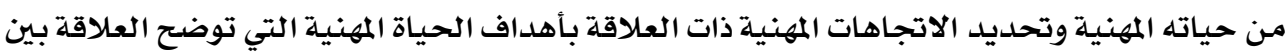

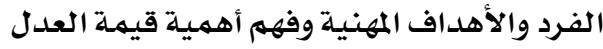


جدول رقم 1

يبين المتوسطات الحسابية والانحرافات المعيارية لفقرات المجال السابع مرتبة تنازليا حسب المتوسطات

الحسابية

\begin{tabular}{|c|c|c|c|c|}
\hline الانحراف & المتوسط & الفقرات (أولياء الأمور) & الرقم & الرتبة \\
\hline $1, \cdot 9$ & r, r & توجيـ اولياء الأمور أبناءهم نحو المهن المطلوبة & 1 & 1 \\
\hline I,r & $r, r$ & توضيح أولياء الأمور لأبنائهم أهمية امتلاك & r & r \\
\hline 1,11 & r,৭^ & تعزيز أولياء الأمور لقيمـة العمل اليدوي لدى أبنائهم & $\varepsilon$ & r \\
\hline $1, \cdot 0$ & $r, 79$ & حث أولياء الأمور أبناءهم على الأنتحاق بههن & r & $\varepsilon$ \\
\hline
\end{tabular}

يبين الجدول رقم ^ ان الفقرة ا حازت على أعلى متوسط حسابي وقدره (r.بr) وانحراف معياري قدره (9.,1) وأن الفقرة الثالثة حصلت على أدنى متتوسط حسابي قدره (19,7) وانحراف معياري قدره (0.,1) وقد حصلت الفقرات (r، ع، r) على درجـة متوسطة فمجال أولياء الأمور جاء

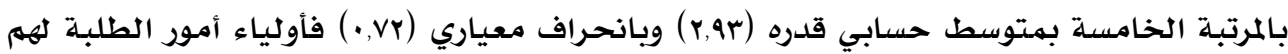
تأثير كبير ِِّ توجيه أبناءهم نحو المهن كما ان توضيح اولياء الأمور اهمية امتلاك المهارات اليدوية وتعزيزهم لقيمة العمل اليدوي، واهميته لدى أبنائهم مما يحفزهم على الالتحاق بالمهن وقد اتفقت

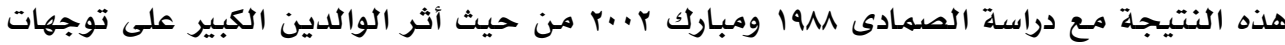
الوالدين ودراسة الفياض 19AV من حيث أثر توجيهات الأبناء ودراسة أوذويهير وهاكفز ليفلو التي كشفت عن أثر العائلة وبيئة الطلبة على خياراتهم المهنية كما اتفقت مـع دراسـة مبارك ب ... مـن حيث أثر الوالدين يِّ توجهات أبنائهم نحو المهن. 


\section{جدول رقم 9}

يبين المتوسطات الحسابية والانحرافات المعيارية لفقرات المجال الأول مرتبة تنازلياً حسب المتوسطات الحسابية

\begin{tabular}{|c|c|c|c|c|}
\hline الانحراف & المتوسط & الفقرات (مجال الإدارة المدرسية) & الرقم & الرتبة \\
\hline $1, \cdot r$ & $r, 11$ & 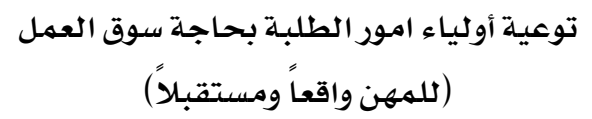 & 1 & 1 \\
\hline $1,1 \mathrm{~V}$ & Y,OY & تسويق الإدارة لإنتاج الطلبة المهني يحفزهم & $r$ & r \\
\hline $1,1 \varepsilon$ & r,rY & تخصيص جوائز لأفضل إنتاج مهني يحفز الطلبـة على اختيار الدراسة المهنية & $r$ & $r$ \\
\hline $1, \cdot 1$ & $I, V \varepsilon$ & إعلان إحصائيات يٌْ مجلات الحائط عن المهن & $\varepsilon$ & $\varepsilon$ \\
\hline
\end{tabular}

يبين الجدول رقم 9 أن الفقرة ا حازت على أعلى متوسط حسابي وقدره (11) (بر) وانحراف

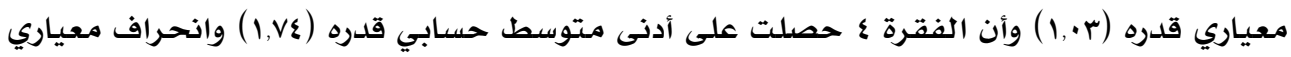

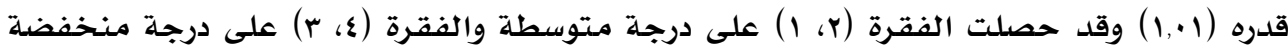

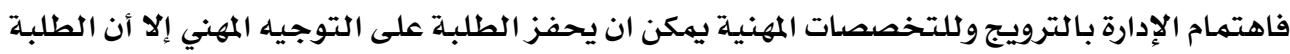

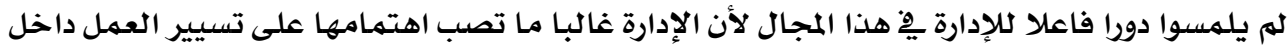
المدرسـة ويتركوا موضوع التوجيه المهني للمتخصصين يِّه هذا المجال من وجهة نظرهم.

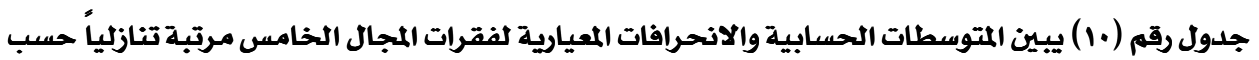

\begin{tabular}{|c|c|c|c|c|}
\hline الانحراف & المتوسط الحسابي & الفقرات (مجال الإذاعة المدرسية) & الرقم - الم & الرتبة \\
\hline ו ו & $r, Y)$ & توضيح مدىى حاجـة سوق العمل للمهـن اليدوية & 1 & 1 \\
\hline $1, \cdot v$ & $r, \bullet$ & الإعلان يفِ الإذاعة المدرسية تقريراً حول المهن & r & r \\
\hline $1, \cdot 7$ & 1,19 & توظيف الإذاعة المدرسية لعمل تمثيليات تحبب & r & r \\
\hline
\end{tabular}


يبين الجدول رقم • 1 ان الفقرة رقم ا حازت على أعلى متوسط حسابي قدره (Y,Y, (Y) وانحراف

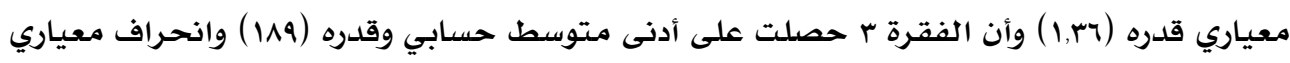

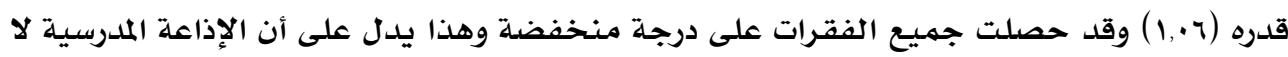

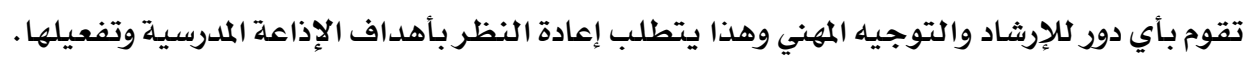

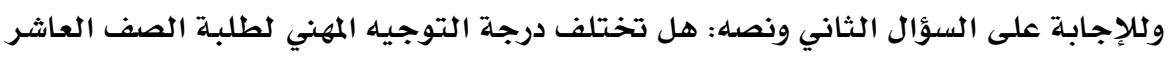

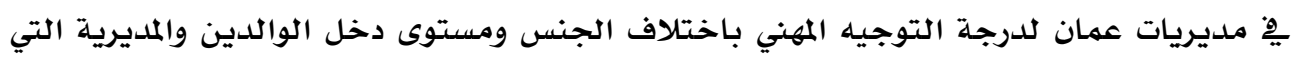

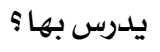

فقد تم استخراج المتوسطات الحسابية والانحرافات المعيارية حسب الجنس، ومستوى الدخل

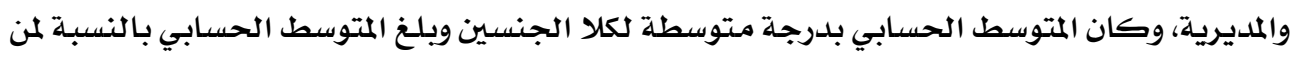

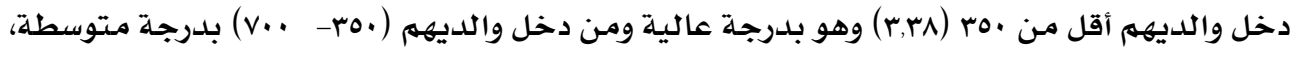

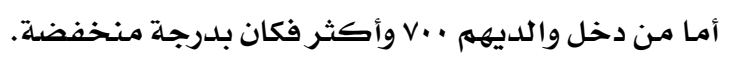

وبالنسبة للمديرية فقط بلغ المتوسط الحسابي لطلبة مديريات عمان الأولى (r,v) وهو

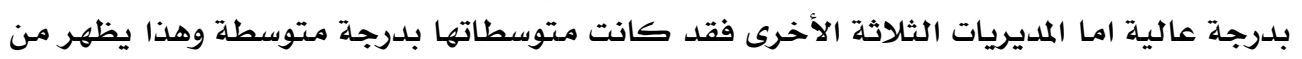

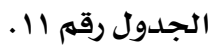

وللكشف عن الفروق بين استجاباتهم حسب المتغيرات المستقلة (الجنس) فقد أظهر تحليل

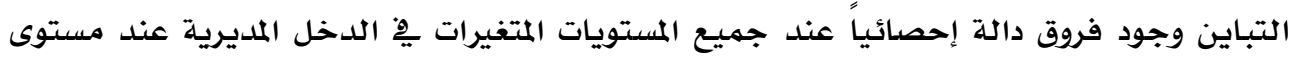

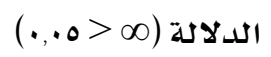

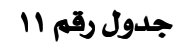

يبين تحليل التباين الثثلاثي

\begin{tabular}{|c|c|c|c|c|c|}
\hline الاحصائية & قيمة ف & متوسط المربعات & درجات & المردمات & مصلر التباين \\
\hline$\cdots$ & דrגומיז & r,rvr & 1 & $r, r v r$ & الجنس \\
\hline$\cdot, \cdots$ & ITY,QVY & ro,०१V & r & 01,194 & الدخل \\
\hline \multirow[t]{4}{*}{$\cdot, \cdots$} & $\varepsilon \tau, \wedge \vee Y$ & V,rer & $r$ & $r Y, \cdot 10$ & المديريـة \\
\hline & & $\cdot, 10 \mathrm{~V}$ & rar & TI, VYo & الخطأ \\
\hline & & & rq9 & IVA,IYV & الكلي \\
\hline & & & & & المجموع \\
\hline
\end{tabular}

وللكثف عن مصادر الفروق فقد تم إجراء مقارنات بعدية بطريقة شفية لأثر الدخل والمديرية لبيان أكبر مصدر للتباين، والجدول رقم با يبين المقارنات البعدية بطريقة شيفيه 
تقديردرجة التوجيه المهني لطلبة الصف العاثرِِ ملديريات تريية عمان من وجهة نظر الطلبة انفسهمر

Scheffe الجدول رقم (r) المقارنات البعدية بطريقة شيفية لأثر الدخل

\begin{tabular}{|c|c|c|c|}
\hline Sig & Mean Difference & (J) الدخل & (I) الدخل \\
\hline $\begin{array}{l}\cdot, \cdots \\
., \cdots\end{array}$ & $\begin{array}{l}\mathrm{VA}(*) \\
1, \cdot \Lambda(*)\end{array}$ & $\begin{array}{l}\text { vo. من.0. أكثر من vo. } \\
\text { vo }\end{array}$ & أقل من • ror \\
\hline $\begin{array}{l}\cdot, \cdots \\
\cdot, \cdots\end{array}$ & $\begin{array}{c}\text { va }-(*) \\
r \cdot .(*)\end{array}$ & 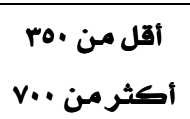 & من (vor . v ) \\
\hline $\begin{array}{l}+, \cdots \\
\cdot, \cdots\end{array}$ & $\begin{array}{l}1, \bullet \wedge-(\bullet) \\
\text { r. }-(\bullet)\end{array}$ & 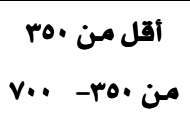 & أكثر من V.. \\
\hline
\end{tabular}

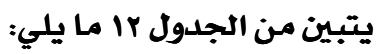

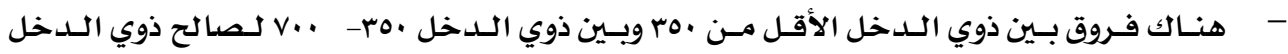

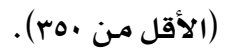

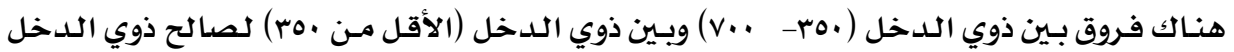

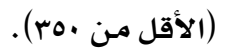

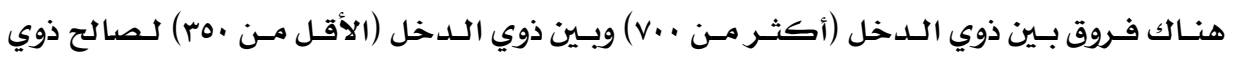

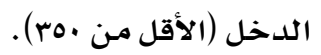

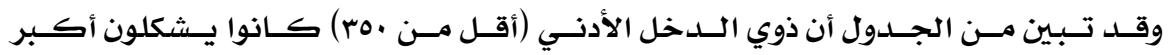

مصدر للتباين.

جدول رقم (r) المقارنات البعدية بطريقة شفيه لأثر المديرية

\begin{tabular}{|c|c|c|c||}
\hline Sig & Mean Difference & (المديرية|| (I) (I) \\
\hline \hline .000 & $092(*)$ & 2 & 1 \\
.000 & $.87(*)$ & 3 & \\
.000 & $.93(*)$ & 4 & \\
& $-92(*)$ & 1 & \\
.000 & -05 & 3 & 3 \\
835 & .01 & 4 & \\
.999 & $-87(*)$ & 1 & \\
.000 & .05 & 2 & 4 \\
.835 & .06 & 4 & \\
.747 & $-93(*)$ & 1 & \\
.000 & -01 & 2 & \\
.999 & -.06 & 3 & \\
.747 & \multicolumn{2}{|c|}{} \\
\hline
\end{tabular}


هناك فروق بين كل من مديرية تربية عمان الأولى وكل من مديريات تربية عمان الثانية والثالثة والرابعة لصالح مديرية تربية عمان الأولى. هناك فروق بين كل من مديرية تربية عمان الثانية ومديرية عمان الأولى لصالح مديرية تربية

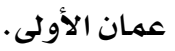
هناك فروق بين كل من مديرية عمان الثالثة ومديرية تربية عمان الأولى لصالح مديرية تربية

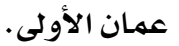
- - - هناك فروق بين كل من مديرية تربية عمان الرابعة ومديرية تربية عمان الأولى لصالح مديرية

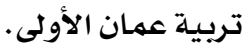

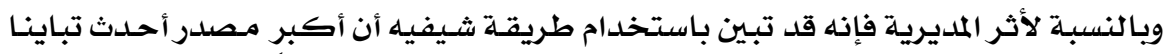

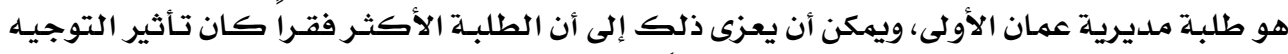

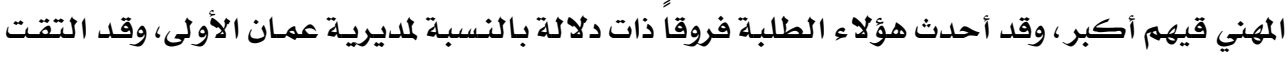

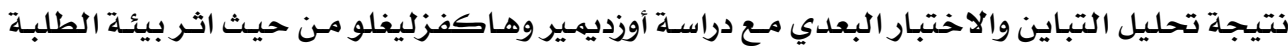

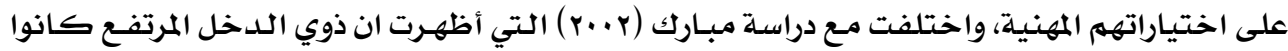

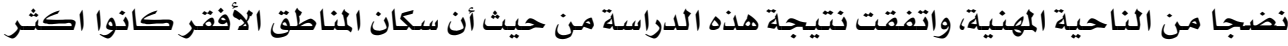

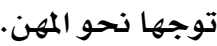

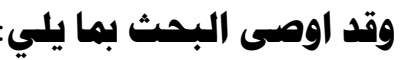

تفعيل دور كل من المعلم والمديروالإذاعة المدرسية لما يمكن أن يحدثوا من تأثير يفٌ التوجيه المهني

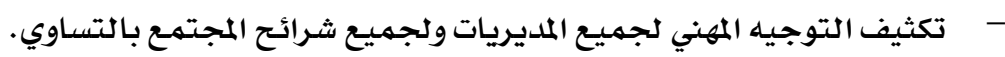

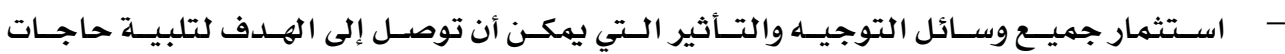




\section{قائمة المراجع}

المراجع باللغة العربية:

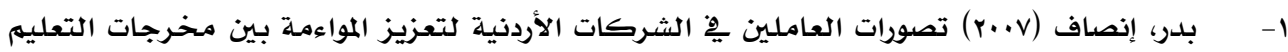

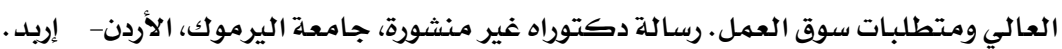

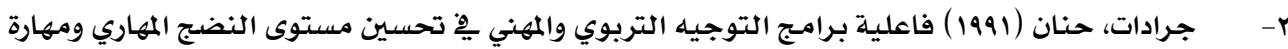

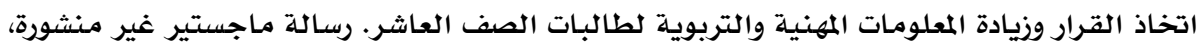

الجامعة الأردنية، الأردن- عمان.

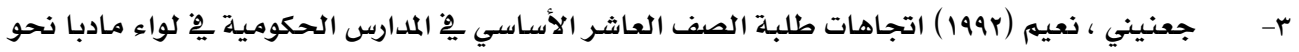

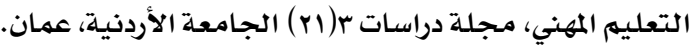

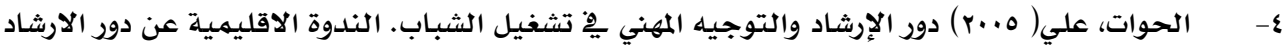

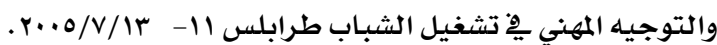

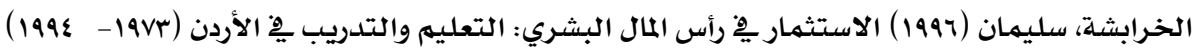
رسالة ماجستير غير منشورة، الجامعة الأردنية، الأردن عمان.

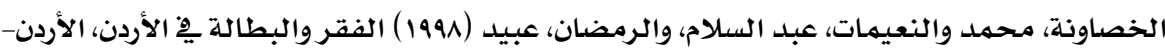
عمان: الجمعينة العلمية الملكية.

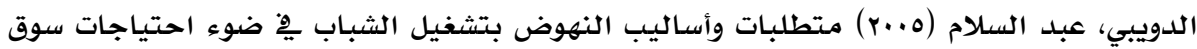

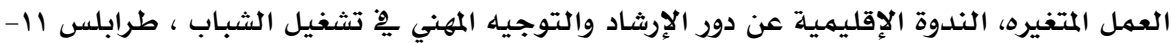
. r...o/v/Ir

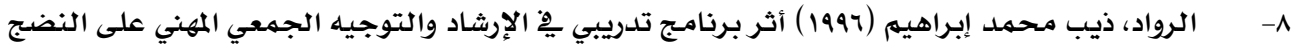

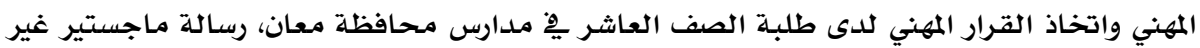

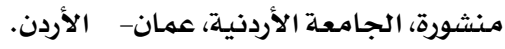

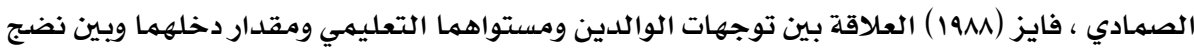

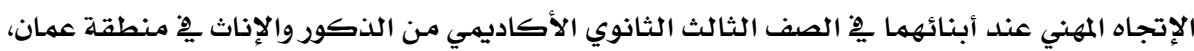
رسالة ماجستير غير منشورة، الجامعة الأردنية، الأردن- عمان عمان.

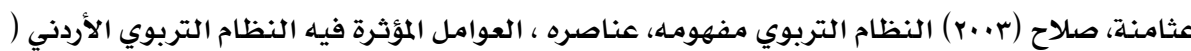

دراسة حالة) جامعة العلوم والتكنولوجيا الأردنية.

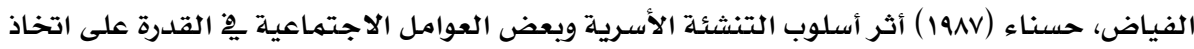

القرار المهني لطلبة الثالث الثانوي. رسالة ماجستير غير منشورة، الجامعة الأردنية، عمان- الأردن.

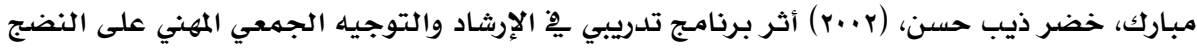

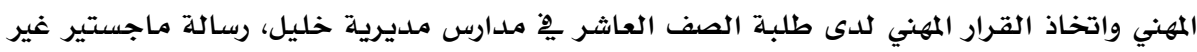
منشورة، جامعة القدس، فلسطين، القدس.

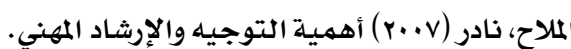




\section{المراجع باللغة الإنجليزية}

1- Guidance \& Counseling in Sweden (2006) http://www/fritzes,es/Njab/EBook.nsf/ByKey/100E06001/\$File/ chapter05.htm.

2- Hamilton,Stephen F.and Hurrelmann, Klaus (1994). The School- to- Career Transition in Germany and the United States. Teachers College Record (96)2.

3- Hasan, Abrar and Wagon Alan (2006) Good Career guidance Could have central role to play in active labor- market policies.

4- Hellman, Shoshana, (2004). Career development stage of Israeli School counserlors, British Journal of Guidance and counseling, (32)1.

5- Jojnson, Ann, And Chope, Robert C., (2005) How can a career counselor work with a whistleblower? Journal of career Development (31) 4.

6- Koplin, Thierry G, and Krumboltz, John (2008) Guidance and school counseling A brief history school guidance and counseling in the united. State.http://education.stateuniversity.com/pages/2023/guidance-counselingschool.html.

7- Mulvy, M. Rachel (2006) Career Guidance in England retrospect and prospect,. British Journal of Guidance and Counseling (34)1.

8- Ozdemir, Nesrin, and Hacifiazliogu, Ozge (2008) Influence of Family and Environment on Students occupational choices and expectations of their prospective. Universalities. Social Behavior and Personality (36).4.433-446.

9- $\quad$ Pinquart, Martin and Juang, Linda P, and Sillbereisen, Rainer K.

10- Primozic, Marjeta and Hasliger, Natasa and Kopac, Anja (2008) Vaupotic Karmen and Haslinger, Natasa and Kopac, Anja (2008) The Role of Career guidance in ensuring equal opportunities of young people in labour market. http://www/huidance-europe.org.english/solvenia/discussion.

11- Pyle, Wanda lee, (1998)The Effect of the National lot Associations career opportunities fair on career decision- making competencies and career choice perceptions of high school student in Los-Angles Country, Dissertation Abstracts, 60(3)9922550-A.

12- Saskatachewan, Regina, (2008) Career Guidance- Acurriculum guidance for middle level-Introduction. http://www/sasked.gov.sk.ca/docs/midcareer/introduct.html.Retreieved6/31/200 $\underline{8}$.

13- Smith,Rex (2008). Career Education and Guidance in New Zealand School. http://www/ieautoserch.com/response.asp?

14- Tsukuda,Naoki(2001). Career Guidance in Japan. Asian Regional Association For Career Development. Country Report.

15- Visser, Coert and Dierolf, Kirsten (2004). Realistic Career guidance.http://www/solutions academy.com/dateien/ realistic20\% Career 20\% guidance,pdf.

16- Watts, Tony (2005) Career Education and Guidance.http://www.sofweb.edu.au/voced/docs/career /trainsion/T=onyWatts. 